\title{
EXPERIMENTAL AND ANALYTICAL STUDY OF REINFORCED CONCRETE BEAMS SHEAR STRENGTHENED WITH DIFFERENT TYPES OF TEXTILE-REINFORCED MORTAR
}

\author{
Christian Escriga ${ }^{*}$, Lluís Gil ${ }^{a}$, Ernest Bernat-Maso ${ }^{a}$, Francesc Puigvert ${ }^{b}$ \\ ${ }^{a}$ Department of Strength of Materials and Structural Engineering. Universitat Politècnica de \\ Catalunya. Colom 11, 08222 Terrassa, Spain
}

b Grasse Zur Composite Testing. Hohentwielsteig 6a, 14163 Berlin, Germany

\begin{abstract}
Textile-reinforced mortar (TRM) is a composite material that overcomes some drawbacks of other RC (reinforced concrete) shear strengthening solutions. In this work, four different types of TRM are used as a shear strengthening system on RC beams tested until failure. A comparative study of their mechanical performance shows that the different TRM combinations used were able to increase the load bearing capacity and change their failure mode. Moreover, new methodologies that permit evaluating the bonding behaviour of TRM and the increment in flexural toughness are presented. The experimental results are compared with previous FRP and TRM analytical formulations. Finally, new formulae for calculating the shear contribution of TRM based on experimental results are proposed.
\end{abstract}

Keywords: Textile, shear, strengthening, experimental, bonding, ductility, analytical.

\section{Introduction}

Today, a sustainable construction strategy requires the enlargement of infrastructure life cycle or changing the use of existing facilities. Ageing and damages reduce the load bearing capacity of the existing infrastructure [1]. Therefore, strengthening structures is a crucial issue for a green economy. In particular, the restoration and repair of reinforced concrete (RC) structures usually requires strengthening activities.

The need for higher capacity of shear stirrups is a case of special concern because shear failure is sudden and the corresponding collapse is difficult to foresee. Traditional shear reinforcements of concrete structures include additional stirrups and increasing the size of the cross section [2]. Another technique uses the external post tensioning of the structure. On the other hand, external steel plates can be attached by adhesives or anchors to both sides of the beam [3,4]. Improvements in composite technologies and reduction of manufacturing costs have created a new generation of solutions that spread in construction 30 years ago. FRP (fibre-reinforced polymer), a family of materials that was born in the aerospace industry, is commonly used in repair work [5]. In general, these materials can have a higher strength to weight ratio than traditional strengthening materials such as concrete and steel. They are easier to transport, cut and cast-in-place, allowing for shorter construction time.

Nevertheless, the use of organic resins classifies this latest reinforcement technique as an environmentally unfriendly solution, which also implies technical issues as noted in the work by Triantafillou and Papanicolaou [6]. Early FRP developments focused on substituting polymeric matrices for cement-based inorganic matrices. A promising alternative came from TRM (textile-reinforced mortar), a new composite material consisting of a fabric as a tensile withstanding material, where the fibres are grouped in tows and arranged as a mesh, which is embedded in a cementitious matrix. Mortar plays two roles as a matrix and an

${ }^{*}$ Corresponding author:

Tel.: +34 937398728; fax: +34 937398994

e-mail address: christian.escrig@upc.edu 
adhesive to the existing structural surface. Although TRM was intended as part of prefabricated structures [7] (it is also known as textile-reinforced concrete, TRC), a significant part of their development focused on the external reinforcement of masonry structures. Studies on masonry walls subjected to in-plane loads [8], out-of-plane loads [9], eccentric compression [10], and applications on masonry arches [11] showed that TRM performs properly as a reinforcement material for masonry structures. This fact has stimulated many manufacturers to develop products (mortars and textiles) specifically designed for the reinforcement of masonry elements.

TRM was also used as a shear strengthening system of RC structures, and it was compared with FRP solutions. Triantafillou and Papanicolaou [12] studied the structural response of RC beams reinforced with carbon textiles using organic and cement matrices. Blanksvärd et al. [13] analysed the behaviour of different fabrics of carbon fibres combined with various types of mortars and resins. Al-Salloum et al. [14] compared the behaviour of beam-column joints reinforced with FRP and TRM and subjected to cyclic loads.

Moreover, Brückner et al. [15] found the relationship between the number of layers of glass textiles and the increase in the shear capacity of structural elements. They also studied the relationship between the bonding performance of TRM and the lengths of fibre anchorage and different layouts of mechanical anchors [16]. Similarly, Al-Salloum et al. [17] investigated the performance of basalt textiles for TRM and analysed the influence of the number of layers and the orientation of fabrics on the shear capacity of reinforced beams. Recent studies $[18,19]$ confirmed the feasibility of shear strengthening RC beams with TRM under static and cyclic loads.

Finally, Si Larbi et al. [20] studied the feasibility of strengthening RC beams with different shapes of TRM precast plates bonded to the concrete surface with epoxies. Related with this application method, Contamine et al. [21] identified the failure mechanisms in concrete beams by comparing precast TRM reinforcing plates and in situ applied TRM.

At the end of 2013, the first version of a design guide was published for TRM external reinforcements, ACl 549.4R-13 [22], with a proposal for TRM shear strengthening. Previously, other authors proposed analytical models $[12,13,20]$ based on reference FRP standards: fib-Bulletin 14 [23] and ACl 440.2R-08 [24].

Preceding works carried out on RC beams strengthened with TRM against flexural failure showed that the use of different combinations of textiles and mortars directly affects their load bearing capacity $[25,26]$. However, it is not known if this comparison can also be extrapolated to shear reinforcement because stress states are completely different. Thus, this paper presents a comparative analysis of the mechanical behaviour of RC beams strengthened in shear with different types of TRM. With this aim, an experimental program was carried out, where 9 RC full-scale beams were tested using four different TRM solutions for shear strengthening. Furthermore, two new methodologies are proposed to evaluate (1) the bonding behaviour of TRM and (2) the increment in flexural toughness that these materials provided. This paper includes a critical study about the applicability of various existing analytical models: TRM shear strengthening from $\mathrm{ACl}$ code [22] and formulations from FRP adapted to a cement matrix [23,24]. Finally, this work proposes an analytical method for determining the contribution of the TRM to the shear resistance of RC beams, which is based on a novel formulation of the effective strain of the TRM $\left(\varepsilon_{f e, T R M}\right)$. 


\section{Materials and specimen preparation}

\subsection{Reinforced concrete beams}

For the experimental campaign, 9 beams were designed and built with a lack of shear reinforcement in two particular areas, as shown in Figure 1. Beams had a length of $1.70 \mathrm{~m}$ and a cross-section of $300 \mathrm{~mm} \times 300$ $\mathrm{mm}$. Three longitudinal reinforcement bars of $\varnothing 16 \mathrm{~mm}$ were installed on the top and the bottom; 5 transverse reinforcement stirrups of $\varnothing 8 \mathrm{~mm}$ were also installed. All reinforcement bars were B500S. Three different batches of concrete were used. The mechanical properties of the concrete and steel are summarized in iError! No se encuentra el origen de la referencia. and were obtained according to the specifications of EN 12390-1 [27], EN 12390-3 [28] and EN ISO 15630-1 [29]. One of the specimens was a control beam, and the other 8 were strengthened with different TRM combinations. All specimens were cured in ambient conditions for more than 30 days.
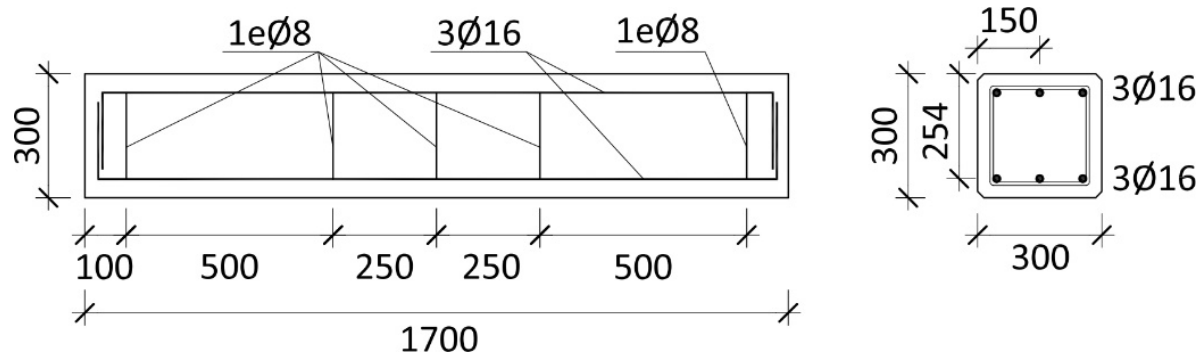

Figure 1. Geometry and steel reinforcement of the tested beams (all dimensions in $\mathrm{mm}$ ).

Table 1. Mechanical properties of the concrete and steel bars.

\begin{tabular}{ccc|ccc}
\hline \multicolumn{3}{c|}{ Concrete } & \multicolumn{3}{c}{ Steel } \\
\hline Cast batch & $\boldsymbol{f}_{\boldsymbol{c m}}[\mathbf{M P a}]$ & $\boldsymbol{E}_{\boldsymbol{c}}[\mathbf{G P a}]$ & $f_{y}[\mathbf{M P a}]$ & $\boldsymbol{f}_{u}[\mathbf{M P a}]$ & $\boldsymbol{E}_{\boldsymbol{s}}[\mathbf{G P a}]$ \\
\hline Batch-1 & 34.07 & 32.92 & & & \\
Batch-2 & 33.78 & 32.83 & 517.20 & 633.63 & 198.48 \\
Batch-3 & 40.85 & 34.82 & & & \\
\hline
\end{tabular}

\subsection{TRM components}

Mortars

Mechanical properties of the TRM mortar matrices are included in Table 2. Tests to determine the compressive and flexural strength were carried out according to EN 1015-11 [30]. Moreover, tensile strength values calculated from the flexural strength according to Bernat [31] are also included. Bonding strength values were provided by the manufacturers, who used double-shear push tests to determine the values. Four types of mortar were used:

- Bicomponent mortar (designated as PHDM) with high strength cement, glass fibres, selected aggregates and synthetic polymers in aqueous dispersion. It is a material specially designed for masonry, and it can also be used as a restoration mortar.

- Hydraulic mortar (designated as XM750) with high bonding capacity, fibres and special additives. It is a mortar designed for application in concrete structure repairing.

- Hydraulic puzzolanic mortar (designated as XM25) with additives. This mortar is perfectly compatible in terms of chemical, physical and mechanical properties with masonry structures. 


\section{5} 6 7 8 19 0

Table 2. Mechanical properties of the mortars used as TRM matrices.

\begin{tabular}{ccccc}
\hline Mortar & $\begin{array}{c}\text { Compression } \\
\text { strength } \\
(\mathbf{M P a})\end{array}$ & $\begin{array}{c}\text { Flexural } \\
\text { strength } \\
(\mathbf{M P a})\end{array}$ & $\begin{array}{c}\text { Tensile } \\
\text { strength } \\
(\mathbf{M P a})\end{array}$ & $\begin{array}{c}\text { Bonding } \\
\text { strength }^{(*)} \\
(\mathbf{M P a})\end{array}$ \\
\hline PHDM & $35.40(2.53)$ & $8.63(0.57)$ & $3.81(0.57)$ & 2.0 \\
XM750 & $30.02(2.21)$ & $10.65(0.80)$ & $4.70(0.80)$ & - \\
XM25 & $24.95(1.64)$ & $7.87(0.78)$ & $3.47(0.78)$ & 0.8 \\
R3 & $24.65(1.43)$ & $8.13(0.99)$ & $3.59(0.99)$ & - \\
\hline
\end{tabular}

Values in brackets indicate coefficient of variance.

${ }^{(*)}$ Values provided by manufacturer.

\section{Textiles}

Textiles consisting of mesh basalt fibres (designated as B), mesh carbon fibres (C), mesh Poliparafenilbenzobisoxazole - PBO fibres (P) and mesh glass fibres (G) were used (Figure 2). Mechanical and geometrical properties of the fibres and textiles provided by the manufacturers are summarised in Table 3 . According to these data, PBO fibres are those that have greater strength and higher Young's modulus. PBO is the only fabric that works unidirectionally, while the other fabrics are bidirectional, meaning that each fabric has the same properties in both principal directions. Notice that basalt fibres are those with a higher ultimate elongation capacity and a greater equivalent thickness of the textile (equivalent performance for a continuous distribution of fibres). Finally, glass textiles are those having a larger cell size of mesh.

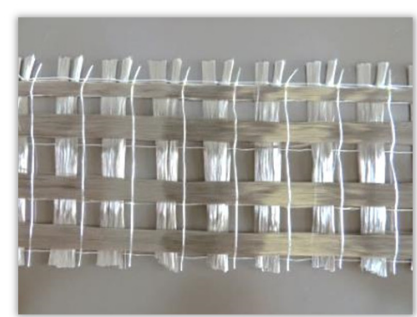

(a)

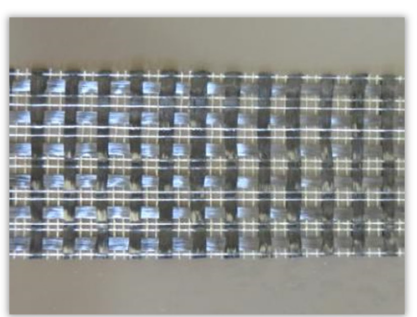

(b)

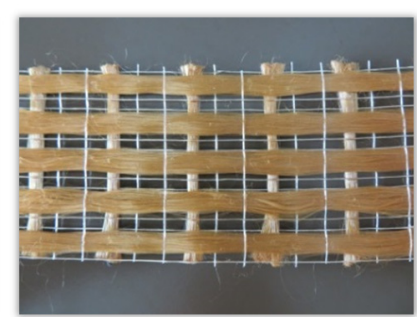

(c)

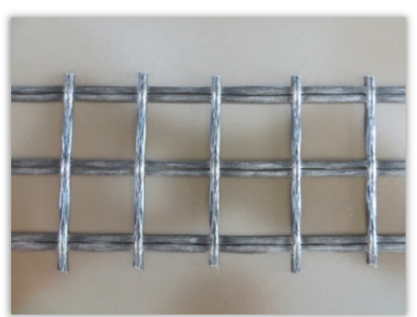

(d)

Figure 2. Textiles used: (a) basalt, (b) carbon, (c) PBO and (d) glass. 1 
Table 3. Properties of the fibres and textiles.

\begin{tabular}{|c|c|c|c|c|c|c|}
\hline & Type of fibre & & Basalt & Carbon & PBO & Glass \\
\hline & Designation & & B & $\mathrm{C}$ & $P$ & $\mathrm{G}$ \\
\hline \multirow{4}{*}{ Fibres } & Fibre orientation ${ }^{a}$ & & $\mathrm{Bi}$ & $\mathrm{Bi}$ & Uni & $\mathrm{Bi}$ \\
\hline & Ultimate tensile strength & $f_{f i b}[M P a]$ & 2990 & 4320 & 5800 & 2610 \\
\hline & Young modulus & $E_{f i b}[G P a]$ & 95 & 240 & 270 & 90 \\
\hline & Ultimate strain & $\varepsilon_{f i b}[\%]$ & 3.15 & 1.80 & 2.15 & 2.90 \\
\hline \multirow{4}{*}{ Textile } & Weight & $w\left(g / m^{2}\right)$ & 200 & 168 & 88 & 225 \\
\hline & Wide of tow ${ }^{b}$ & $w_{m}(m m)$ & 5 & 4 & 5 & 3 \\
\hline & Distance between tows ${ }^{b}$ & $s_{m}(m m)$ & 15 & 10 & 10 & 25 \\
\hline & Equivalent thickness ${ }^{b}$ & $t_{t e x}(m m)$ & 0.053 & 0.047 & 0.0455 & 0.042 \\
\hline
\end{tabular}

${ }^{a} \mathrm{Bi}=$ Bidirectional; Uni=Unidirectional.

${ }^{b}$ In the unidirectional case, the properties given are in the principal direction of the reinforcement.

3 Different combinations of textiles and mortars were used to produce in situ TRM shear strengthening for 4 the concrete beams, except for the control beam (designated as V-CONTROL). All applied combinations 5 follow the $\mathrm{V}-\mathrm{AB}-\mathrm{C}$ nomenclature, where $\mathrm{A}$ stands for the type of textile, $\mathrm{B}$ indicates the type of mortar, and $6 \mathrm{C}$ is the test number. Table 4 summarizes the different specimens, TRM combinations of the components 7 and the date of each batch of concrete. The mechanical properties of TRM strengthening solutions as a 8 composite material were obtained from different literature sources [22,32] and manufacturer information 9 (Table 5).

Table 4. TRM combinations used as shear reinforcement of RC beams.

\begin{tabular}{cccc}
\hline Specimen & Textile & Matrix & Concrete batch \\
\hline V-BR3-01 & Basalt & R3 & Batch-2 \\
V-BR3-02 & Basalt & R3 & Batch-2 \\
V-CXM25-01 & Carbon & XM25 & Batch-2 \\
V-CXM25-02 & Carbon & XM25 & Batch-1 \\
V-PXM750-01 & PBO & XM750 & Batch-1 \\
V-PXM750-02 & PBO & XM750 & Batch-1 \\
V-GPHDM-01 & Glass & PHDM & Batch-2 \\
V-GPHDM-02 & Glass & PHDM & Batch-1 \\
V-CONTROL & - & - & Batch-3
\end{tabular}

Table 5. Mechanical properties of TRM strengthening composite materials.

\begin{tabular}{llcccc}
\hline & & BR3 $^{\boldsymbol{a}}$ & $\mathbf{C X M 2 5}^{\boldsymbol{b}}$ & $\boldsymbol{P X M 7 5 0}^{\boldsymbol{b}}$ & $\mathbf{G P H D M}^{\boldsymbol{c}}$ \\
\hline \multicolumn{1}{c}{ Cracked TRM Young's modulus } & $E_{f}[\mathrm{GPa}]$ & 48 & 80 & 128 & 90 \\
\multicolumn{1}{c}{ Ultimate strain } & $\varepsilon_{f u}[\%]$ & 1.65 & 1.00 & 1.76 & 1.19 \\
\hline${ }^{a}$ Larrinaga, 2011 [32] & & & & & \\
${ }^{b} \mathrm{ACl}$ 549.4R-13, 2013 [22] & & & & &
\end{tabular}




\subsection{Reinforcement application}

After a minimum of 30 days of curing, 8 beams were shear strengthened by the U-shaped jacket system. To simulate a real strengthening case where cost is an important factor, only the zone with a lack of shear stirrups at each end of the beam ( $500 \mathrm{~mm}$, see Figure 1 ) was reinforced with TRM that included a single layer of fabric. The strengthening process included the following steps:

a) Removing, by mechanical means, the fine grain of the concrete surface in areas where the TRM (Figure 3a) should be placed. This operation maximizes the bonding compatibility between existing concrete and mortar and prevents debonding failure [15].

b) Wetting the concrete surface with the aim of avoiding water transfer from the fresh TRM mortar to the concrete (Figure $3 \mathrm{~b}$ ).

c) Applying the first layer of fresh mortar with a thickness of 4-5 mm using a steel trowel and then immediately placing the textile on the mortar, orienting the principal direction of the textile perpendicular to the longitudinal axis of the beam.

d) Embedding the textile into the fresh mortar with a soft pressure. During this operation, the mortar should penetrate through the tows of the mesh (Figure 3c). Then, a second mortar layer is applied to achieve a total thickness of approximately $10 \mathrm{~mm}$.

e) Finally, smoothing the surface of the mortar with the help of a trowel (Figure 3d).

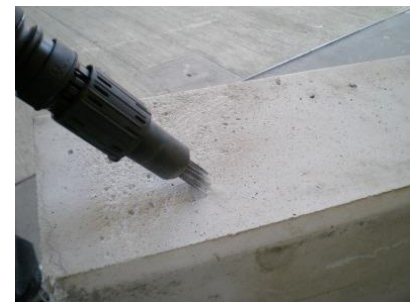

(a)

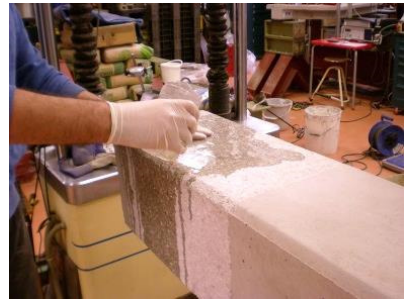

(b)

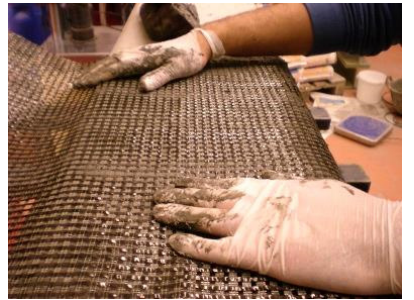

(c)

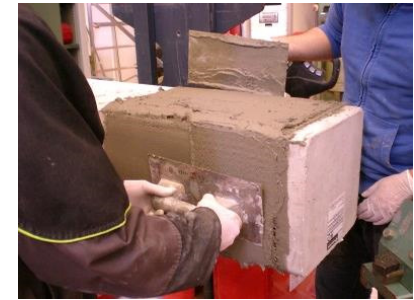

(d)

Figure 3. TRM application process.

All reinforced specimens were cured in laboratory conditions for at least 28 days prior to testing.

\section{Experimental campaigns}

\subsection{Test set-up}

All beams were tested under a three-point flexural test with a free span between supports of $1.50 \mathrm{~m}$. The section where the load was applied was shifted $50 \mathrm{~mm}$ from the centre of the beams to avoid the short shear span effect, at least in one-half of the geometry. Figure 4 shows the test set-up where zones 1 and 2 correspond to the shear spans with a length of $700 \mathrm{~mm}$ and $800 \mathrm{~mm}$, respectively.
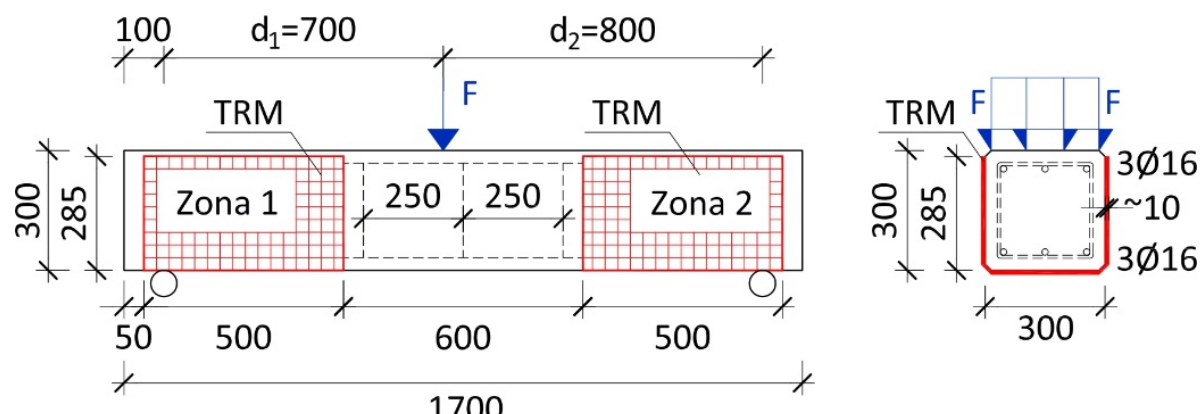
1 The supports consisted of metal cylinders that allowed free rotation of the specimens in the plane of the 2 beam. The tests were carried out using a hydraulic actuator with a maximum capacity of $500 \mathrm{kN}$ under 3 displacement control at $1 \mathrm{~mm} / \mathrm{min}$. A semi cylindrical load transmission tool was utilised to properly apply 4 load to the specimens.

5 The vertical displacement of each beam was measured in three different transversal sections by six 6 potentiometers placed symmetrically in both sides of the beam. These transversal sections correspond to the load application (measuring range of the potentiometers up to $500 \mathrm{~mm}$ ) and the middle of the shear span in both zones (measuring range of the potentiometers up to $100 \mathrm{~mm}$ ) (Figure 5).
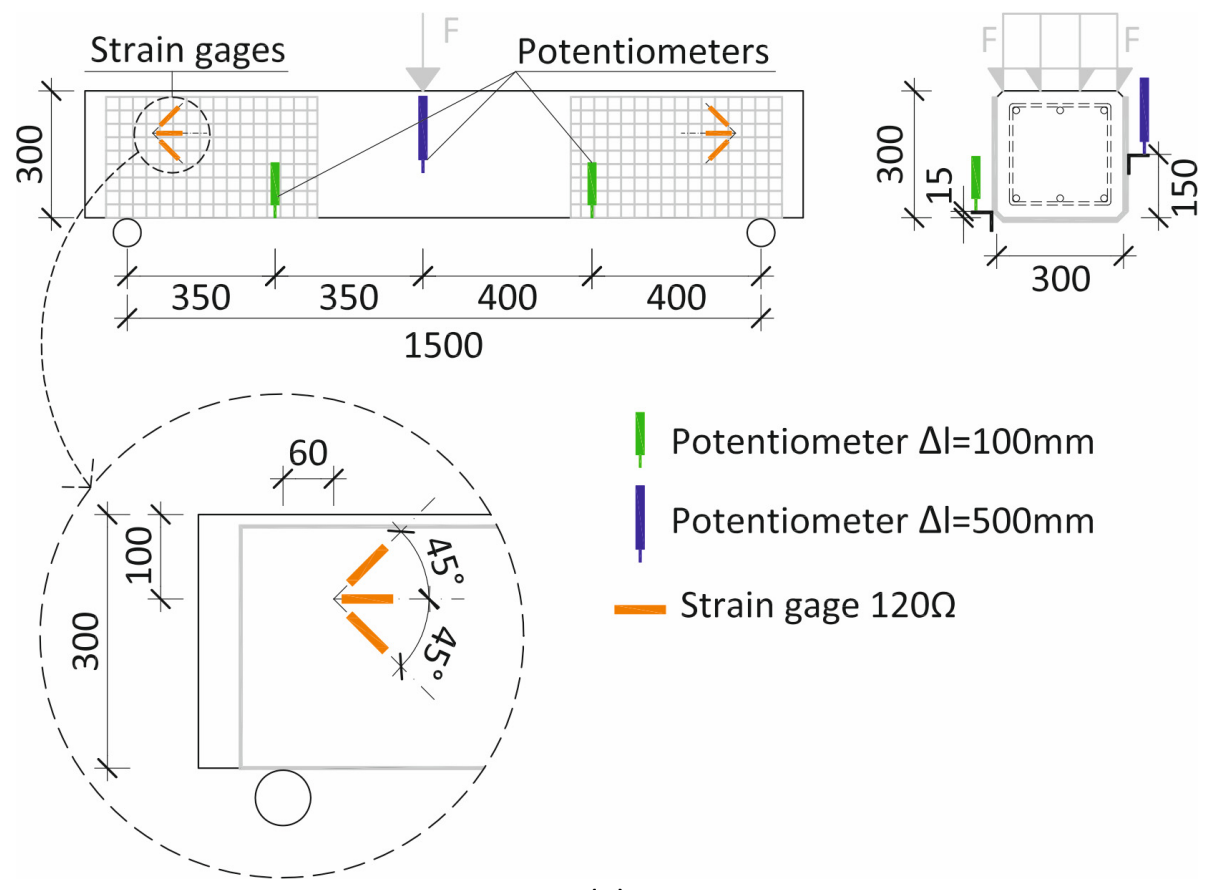

(a)

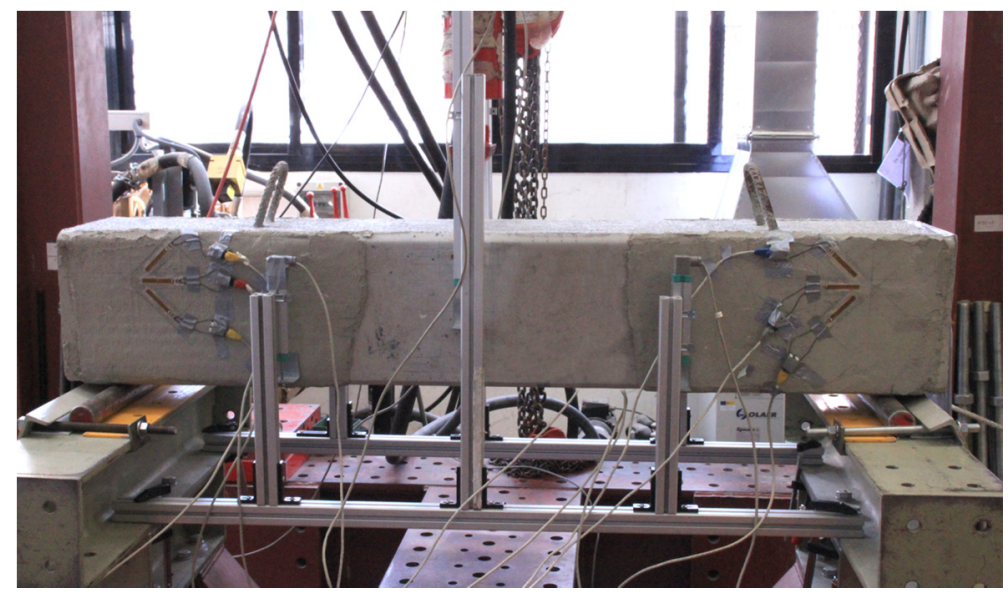

(b)

Figure 5. Test instrumentation: (a) sketch, (b) picture (all dimensions in $\mathrm{mm}$ ).

Load and vertical displacement were continuously recorded to determine the flexural toughness of all specimens. The analysis of this variable allows the failure mechanism ductility and the absorbed fracture energy of each beam to be assessed. 
The flexural toughness was determined according to the Japanese Standard JSCE-SF4 [33] and the modifications proposed by Bernat et al. [34]. This procedure is based on the calculation of the area under the measured force-vertical displacement curves of the specimens up to a maximum beam deflection of $L / 150\left(T E N_{\delta=L / 150}\right)$ and $L / 100\left(T E N_{\delta=L / 100}\right)$, where $L$ is the distance between supports.

The adhesion of the TRM strengthening on the concrete substrate was also investigated through a novel methodology. Strain gages were placed on two different points of the TRM reinforcement surface, avoiding the expected crack development, to obtain the full state of strains on the selected points. Each group of three strain gauges consisted of one gauge placed parallel to the longitudinal axis of the beam and the other two gauges oriented at $\pm 45^{\circ}$ with respect to the first gauge (see Figure $5 \mathrm{a}$ and Figure $5 \mathrm{~b}$ ). The experimental shear strain increments of the TRM $\left(\Delta \gamma_{x y-T R M}\right)$ in zone 2 were compared against the theoretical shear strain increments, which were calculated using the forces equilibrium equations and also considered the beam as an isotropic linear material $\left(\Delta \gamma_{x y-E Q}\right)$.

All data were recorded at a frequency of $50 \mathrm{~Hz}$ using an HBM MGCPlus data acquisition system.

\subsection{Results}

All specimens were tested up to failure. Three different failure modes were observed during the experimental campaign and are defined as follows:
A. Shear failure with the main crack propagating from the load application section towards the bottom of the beam without crossing the TRM strengthened area. Several additional cracks were observed on the concrete: cracks caused by bending and others caused by crushing of the compressed concrete. All of the specimens that developed this failure mode reached the flexural yielding, but they did not fail by bending.
B. Shear failure with the main crack propagating from the load application section towards the support, avoiding the stirrup reinforcement. After failure, the main crack propagated diagonally towards the support.
C. Shear failure with the main crack propagating from the load application section towards the support by crossing both the shear reinforcement stirrup and the TRM strengthened area.

Figure 6 shows the observed failure modes of all tested beams as well as the cracking pattern where the main crack is highlighted. Table 6 summarises the results obtained in the experimental campaign. This table contains the failure mode, the zone where the failure occurred, the ultimate load $\left(F_{\text {max }}\right)$, the vertical displacement of the loaded section at the ultimate load $\left(\delta_{u}\right)$ and the geometric angle between the main crack and the longitudinal axis of the beam $(\theta)$, which was determined through graphical methods. 


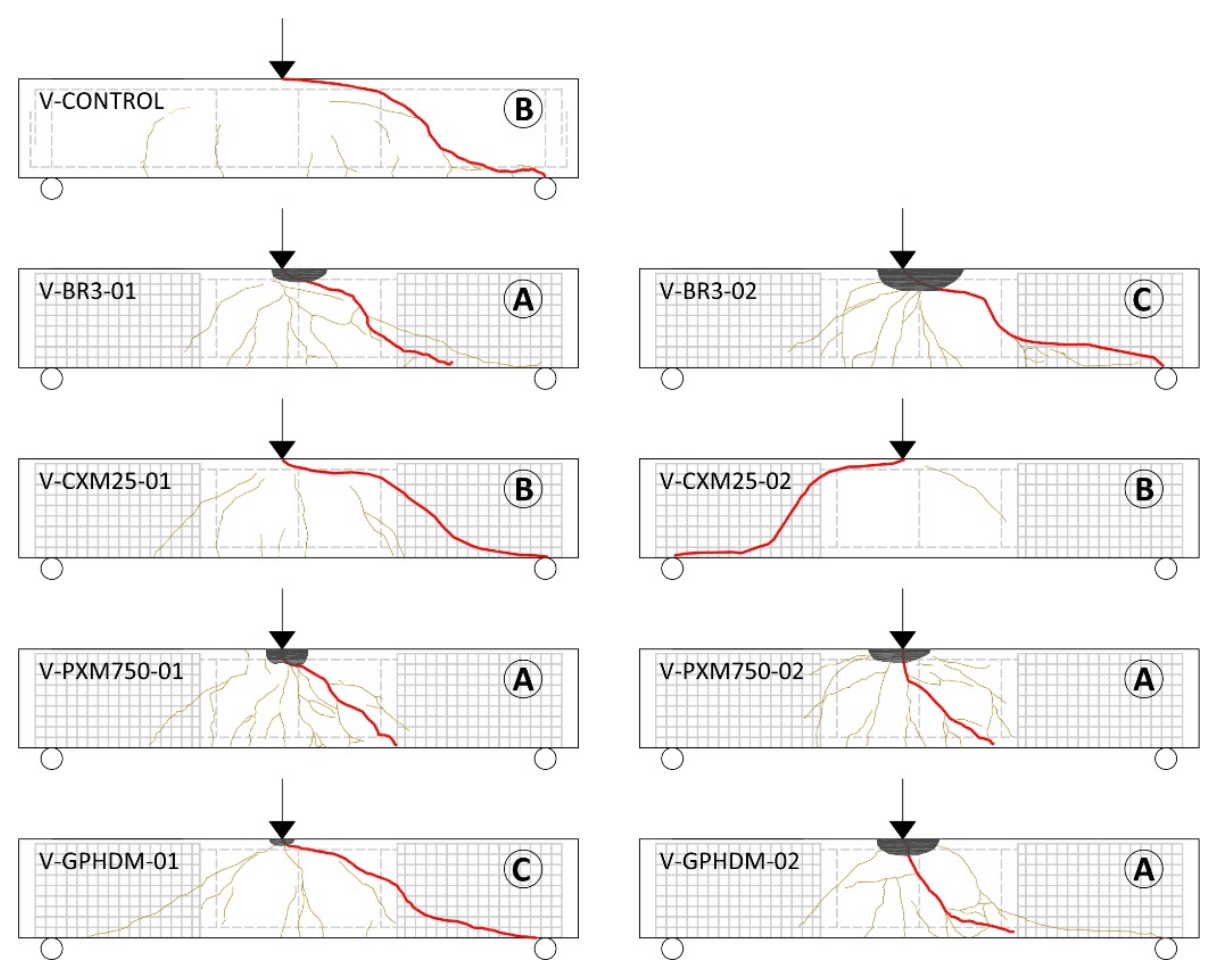

Figure 6. Failure modes of tested beams.

Table 6. Summary of the experimental results.

\begin{tabular}{|c|c|c|c|c|c|c|c|c|}
\hline Specimen & $\begin{array}{c}\text { Failure } \\
\text { mode }\end{array}$ & $\begin{array}{l}\text { Failure } \\
\text { zone }\end{array}$ & $\begin{array}{l}F_{\max } \\
(k N)\end{array}$ & $\begin{array}{c}\delta_{u} \\
(\mathrm{~mm})\end{array}$ & $\begin{array}{c}\theta \\
\left({ }^{\circ}\right)\end{array}$ & $\begin{array}{c}V_{u, \text { exp }, i} \\
(k N)\end{array}$ & $\begin{array}{c}T E N_{\delta=L / 150} \\
(J)\end{array}$ & $\begin{array}{c}T E N_{\delta=L / 100} \\
(J)\end{array}$ \\
\hline$V-B R 3-01$ & $A$ & 2 & 211.02 & 8.28 & 44 & 98.48 & 1453.70 & 2458.47 \\
\hline$V-B R 3-02^{(2)}$ & C & 2 & 130.04 & 36.76 & 21 & 60.69 & 862.18 & 1443.44 \\
\hline$V-C X M 25-01$ & B & 2 & 220.42 & 7.44 & 38 & 102.86 & 1529.00 & 2340.10 \\
\hline$V-C X M 25-02$ & B & 1 & 173.15 & 5.82 & 56 & 92.35 & 1192.46 & 1714.18 \\
\hline$V-P X M 750-01$ & A & 2 & 215.95 & 20.72 & 42 & 100.77 & 1379.49 & 2436.13 \\
\hline V-PXM750-02 & A & 2 & 231.66 & 35.91 & 40 & 108.11 & 1708.29 & 2809.75 \\
\hline V-GPHDM-01 & C & 2 & 104.76 & 7.05 & 33 & 48.89 & 689.32 & 1196.21 \\
\hline V-GPHDM-02 & A & 2 & 219.04 & 8.62 & 46 & 102.22 & 1511.02 & 2582.77 \\
\hline V-CONTROL & B & 2 & 161.59 & 3.97 & 41 & 75.41 & $646.18^{(1)}$ & $646.18^{(1)}$ \\
\hline
\end{tabular}

(1) Test did not reach a vertical displacement of L/150 in the load application section.

(2) Specimens that did not increase the load bearing capacity with respect to the control beam.

4 It is worth mentioning that the individual weight of the beams, which was equivalent to $1.70 \mathrm{kN}$, was considered when calculating the ultimate load $\left(F_{\max }\right)$. Then, the ultimate shear resistance for each specimen was calculated according to Eq. 1:

$$
V_{u, \text { exp }, i}=d_{i} \frac{F_{\max }}{L} \begin{cases}d_{i}=d_{1}=700 \mathrm{~mm}, & \text { failure in zone } 2 \\ d_{i}=d_{2}=800 \mathrm{~mm}, & \text { failure in zone } 1\end{cases}
$$

8 where $L$ is the distance between supports, and $d_{i}$ is the shear span (Figure 4), which can be either $700 \mathrm{~mm}$ 9 or $800 \mathrm{~mm}$ depending on the failure zone. The experimental shear resistances $\left(V_{u, e x p, i}\right)$ are shown in the seventh column of Table 6 . 
1 With the aim of comparing the experiment results of all specimens, the shear forces were normalised, 2 defining $\mu$ (Eq. 2$)$ as the ratio of the experimental shear forces developed in zone $2\left(V_{\text {exp, } 2}\right)$ out of the shear 3 resistance of the concrete structure without the presence of shear reinforcement $\left(V_{c}\right)$, which was calculated 4 according to the standard Eurocode2 [35].

$$
\mu=\frac{V_{\text {exp, } 2}}{V_{c}} \quad \text { Eq. } 2
$$

$5 \quad$ Figure 7 shows the experimental curves of the normalised shear force $(\mu)$ versus the vertical displacement 6 of the load application section $\left(\delta_{F}\right)$ of all specimens for each failure mode. The data of the unstrengthened 7 control beam (V-CONTROL) is included in all cases for comparison purposes. 


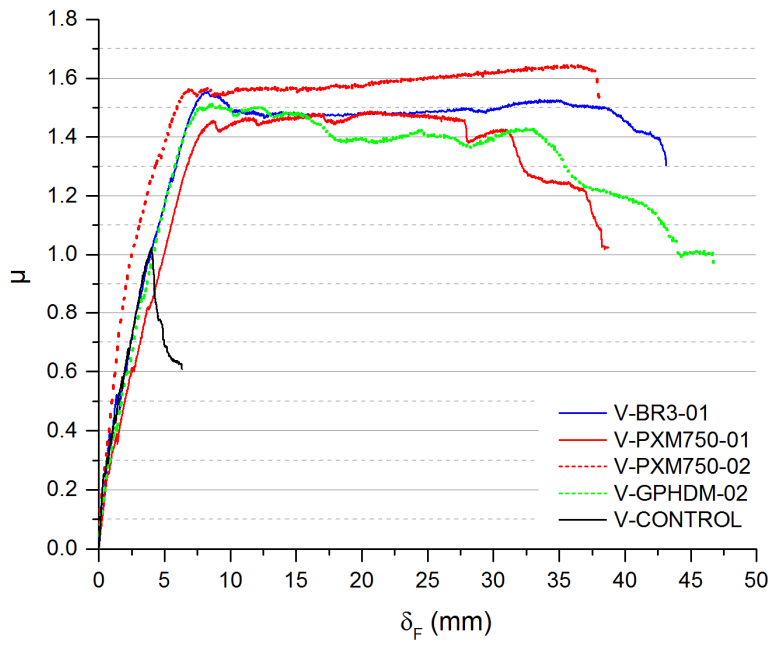

(a)

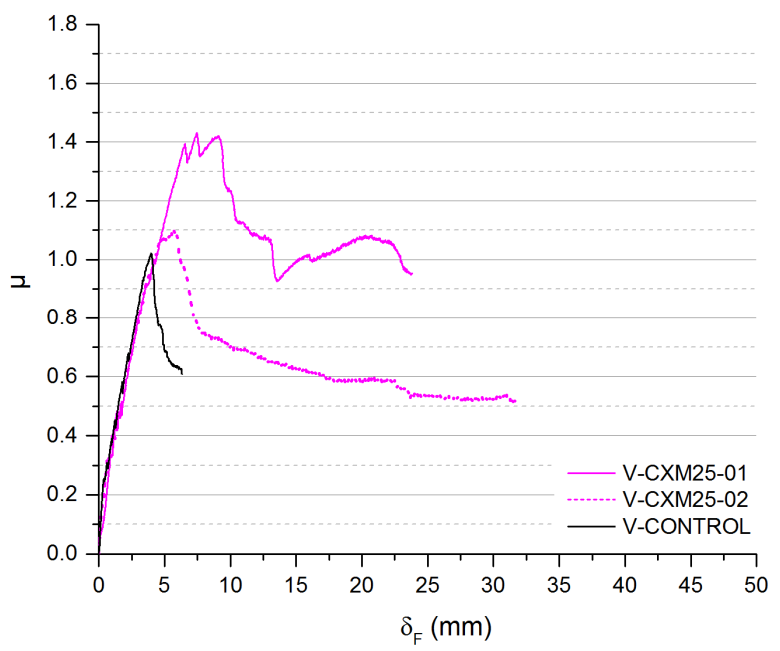

(b)

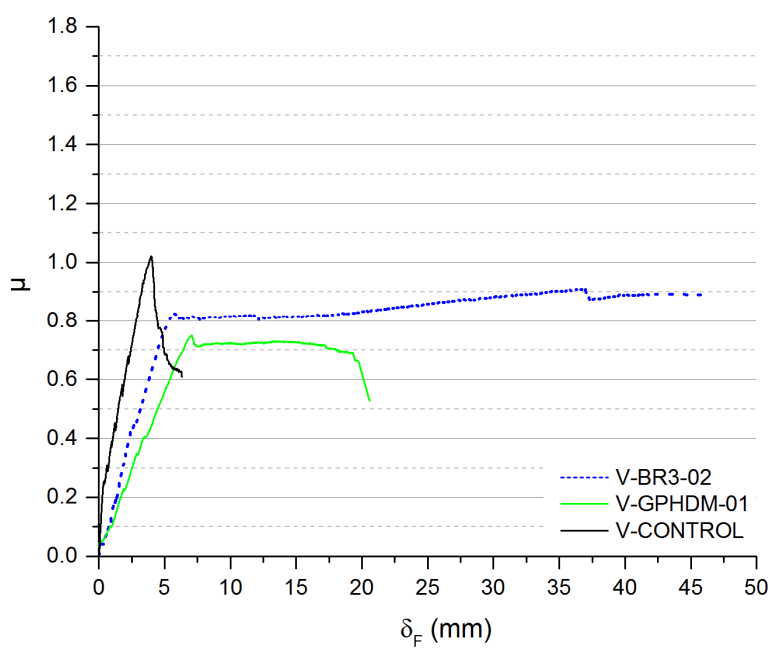

(c)

1 Figure 7. Normalized shear force vs. vertical displacement of the load application sections: (a) failure mode A, (b) failure mode B and (c) failure mode $\mathrm{C}$. The unstrengthened beam is included in all cases. 
It can be observed in Figure $7 c$ that the strengthened beams, which developed failure mode $C$, were unable to reach the normalized ultimate shear force of the control beam. Additionally, according to Figure 8 , the vertical displacement of specimens V-BR3-02 and V-GPHDM-01 at a load of $100 \mathrm{kN}$ was significantly higher than of the other beams, which suggests that these specimens had poor flexural stiffness. This fact could be explained by problems related with the early stages of concrete curing. Despite this, the ductile behaviour of both specimens suggests that TRM reinforcement was activated, avoiding the sudden failure of the beams. Due to their abnormal behaviour, these beams were not considered in the discussion section, the analytical study and the conclusions of the present research.

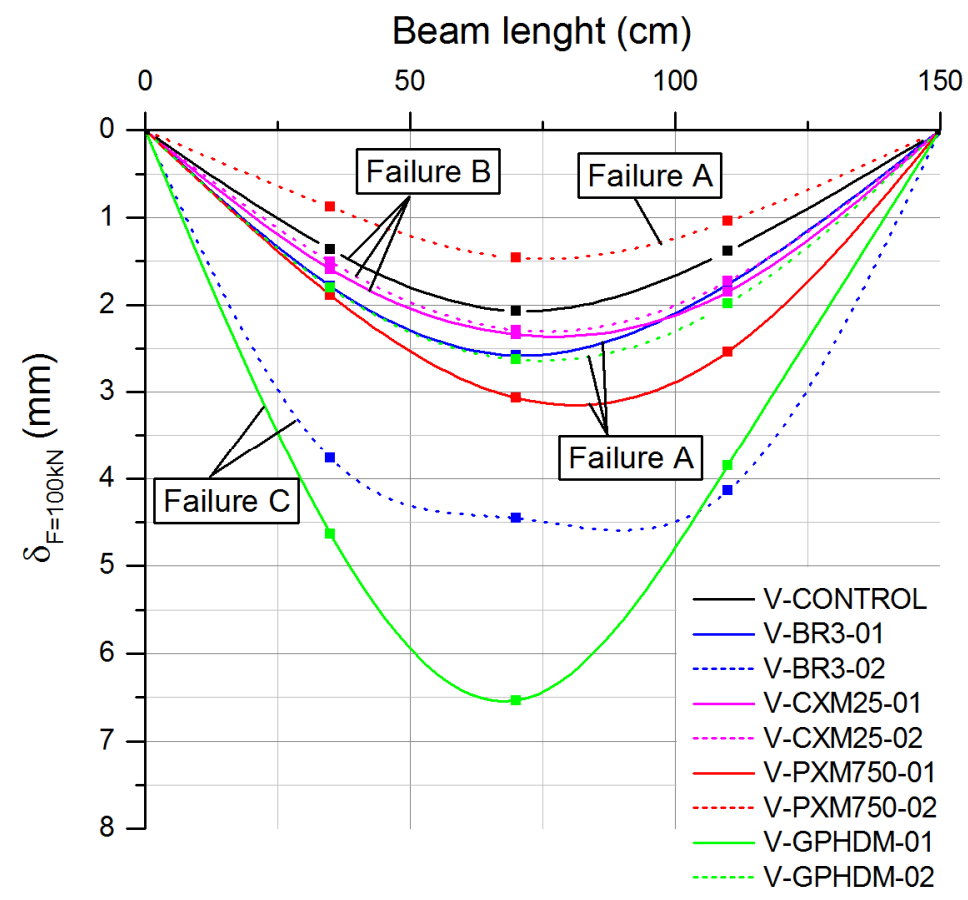

Figure 8. Deflexion of the tested beams at a load of $100 \mathrm{kN}$.

The values of the energy absorbed by the specimens that correspond to the deflections of the load application section of $\mathrm{L} / 150\left(T E N_{\delta=L / 150}\right)$ and $\mathrm{L} / 100\left(T E N_{\delta=L / 100}\right)$ are shown in the last two columns of Table 6 . These values are displayed in Figure 9. It is noteworthy that the control beam (V-CONTROL) did not reach the specified deflections, and therefore, the flexural toughness was determined only for the deflection of the beam at the failure moment. 


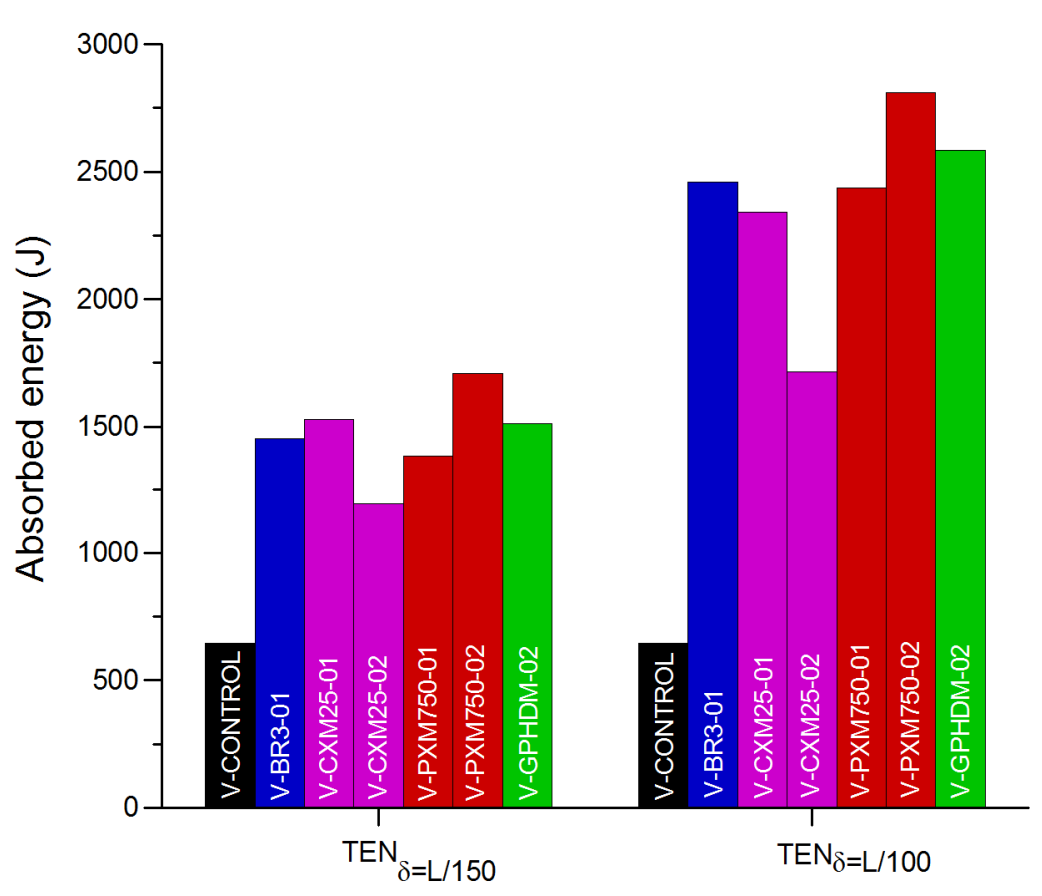

Figure 9. Absorbed energy for vertical displacements of the load application section of $L / 150$ and $L / 100$, except for V-CONTROL, which did not reach these values.

4 Figure 10 compares the experimental shear strain increments of the TRM $\left(\Delta \gamma_{x y-T R M}\right)$ and the theoretical 5 shear strain increments resulting from the force equilibrium equations $\left(\Delta \gamma_{x y-E Q}\right)$ versus the load increment 6 of all strengthened beams. If the experimental curves are higher than the theoretical curves, the measured 7 shear strain on the TRM is lower than the shear strain of the concrete at the same point on the beam. Thus, 8 there are differences between the rotation of the concrete substrate and the rotation of the TRM. This 9 might be understood as an imperfect adherence between the concrete and the TRM and/or between the 10 textile and the mortar of the TRM. This procedure was also conducted for the control beam to validate this 11 new method. 


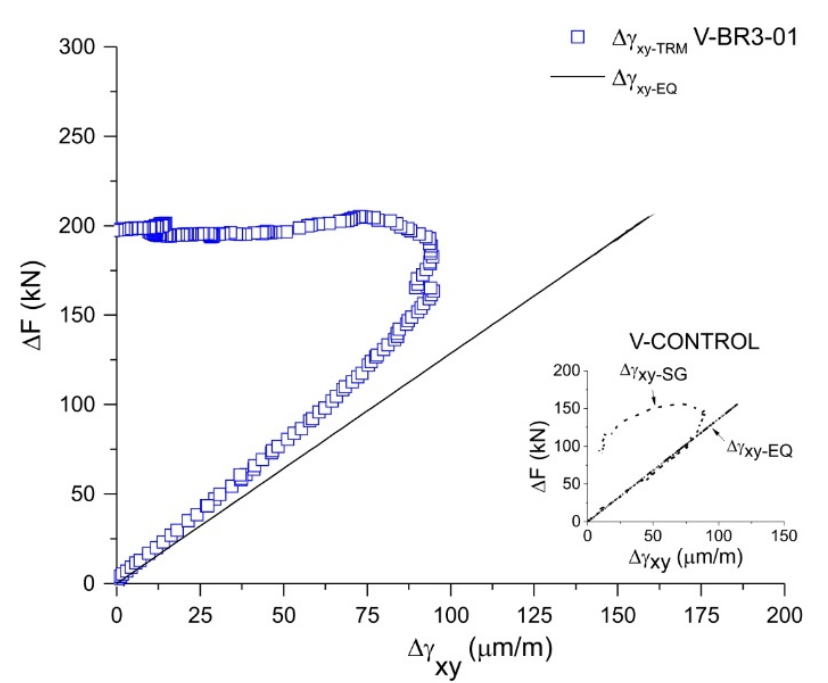

(a)

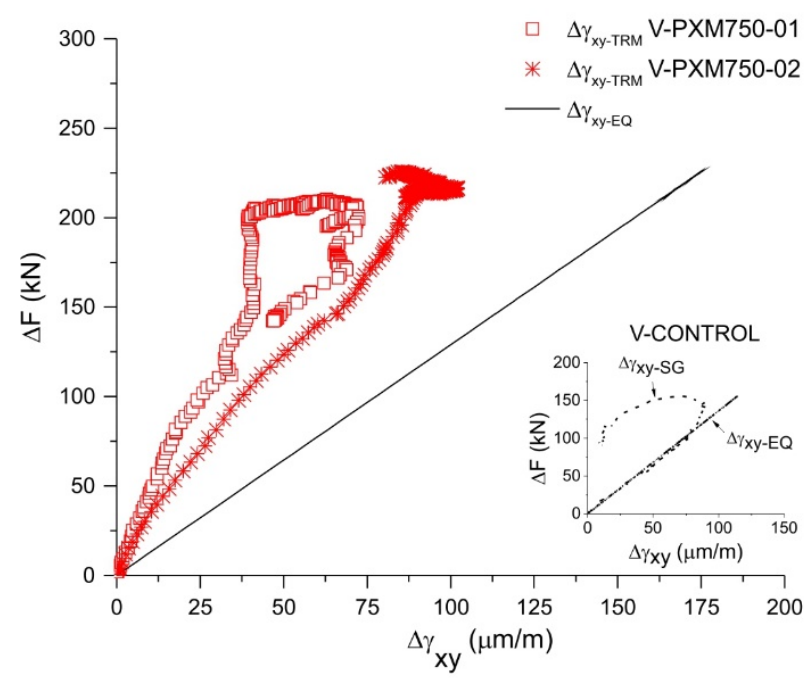

(c)

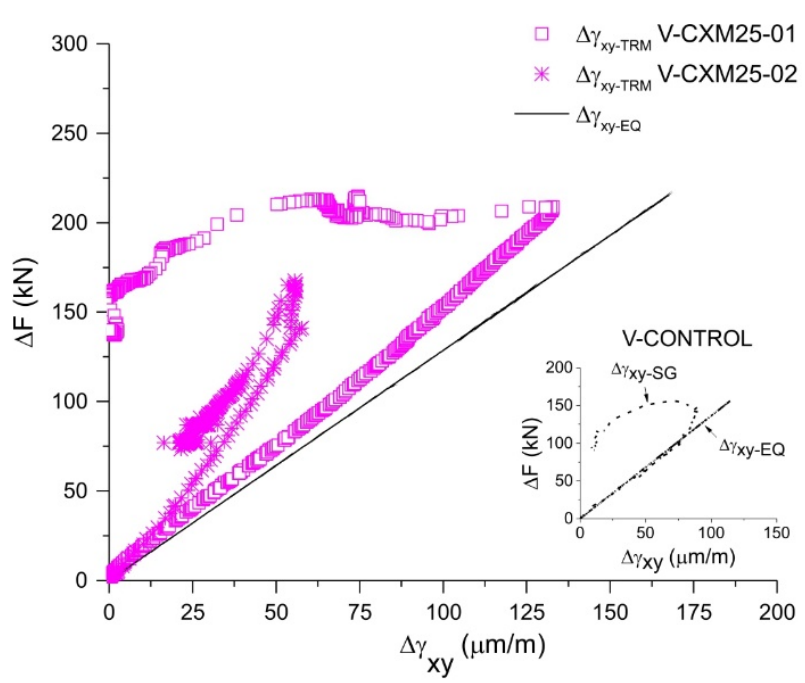

(b)

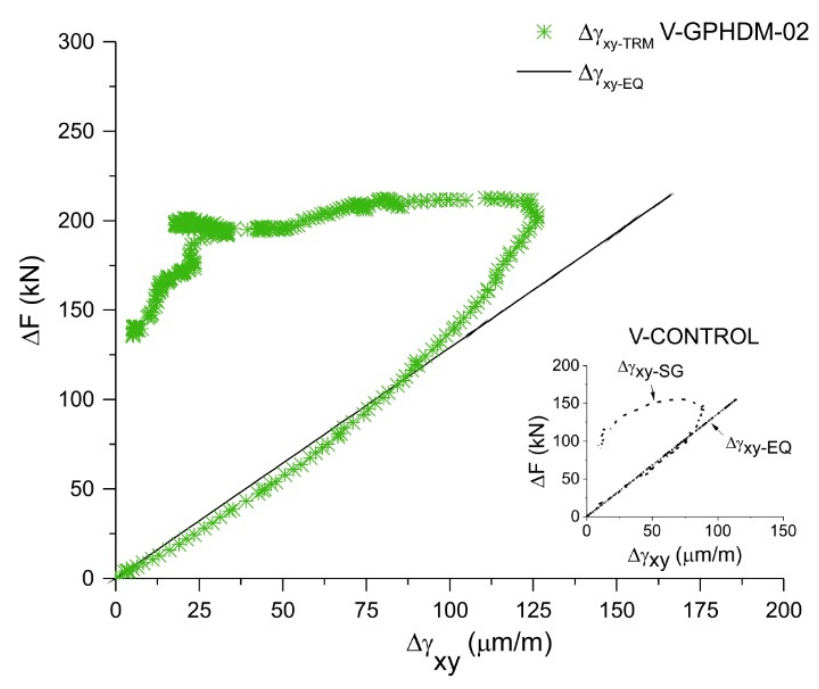

(d)

Figure 10. Real shear strain increase and theoretical shear strain increase vs. load increase: (a) BR3, (b) CXM25, (c) PXM750 and (d) GPHDM.

\section{$4 \quad 3.3$ Comparison and discussion}

\section{Shear strengthening capacity}

Except for the case of specimen V-CXM25-02, the main crack was located in the zone where the shear span was longer. This may be caused by a higher shear capacity than expected in the beam configuration, which was produced by a strut mechanism in zone 1 of the concrete structure due to a short shear span effect.

Figure 7a shows that the specimens that failed according to failure mode A were able to increase the shear ultimate capacity of the concrete structure by an average of over $35.78 \%$. Specimen V-PXM750-02 developed the greatest shear capacity increase (over 43.36\%). In addition, these specimens showed a more ductile response than the control beam, avoiding the sudden failure after completing the linear-elastic response.

Unlike the rest of the specimens, PBO strengthened samples were able to continue with increased load during the nonlinear response. The ultimate load was reached when the deflection of the load application section was between $420 \%$ and $800 \%$ greater than the ultimate deflection of the control beam. 
Although the ultimate tensile strength of basalt and glass fibres is approximately $50 \%$ of the PBO fibres, the beams strengthened against shear with BR3 and GPHDM showed similar mechanical behaviour to the beams strengthened with PXM750. This fact suggests that there are several factors besides the amount of fibres that influence the shear strengthening of concrete structures with TRM, such as textile-matrix and matrix-substrate adhesion.

Specimens strengthened with carbon textiles developed the same failure mode as the control beam (Figure 6 and Table 6). Although the V-CXM25 beams were not able to develop a nonlinear behaviour before sudden failure, these specimens reached a higher ultimate shear force (between $7 \%$ and $36 \%$ ) than the control beam (Figure 7b). According to Bernat et al. [10], the scatter of the results may be due to a deficient adherence between the textile and the mortar, which can affect the strengthening capacity of the specimens. In particular, this is more evident for the strengthened beam V-CXM25-02.

Despite the abnormal behaviour of the two beams that failed according to failure mode $C$, in Figure $7 c$, it can be seen that TRM strengthening contributed to a more ductile response.

\section{Flexural toughness}

According to Table 6 and Figure 9, a higher flexural toughness was reached for all TRM strengthened specimens in comparison with the control beam. The highest flexural toughness was achieved for the specimens strengthened with PBO textiles with respect to the control beam, displaying a maximum average increase of $139 \%$ for a beam deflection of $\mathrm{L} / 150$ and $306 \%$ for a beam deflection of $\mathrm{L} / 100$. These results may be caused by the high elastic modulus and ultimate elongation of PBO fibres. Moreover, the lowest flexural toughness was reached for specimens strengthened with carbon textiles with an average increase, with respect to the control beam, of $111 \%$ and $214 \%$ for beam deflections of $L / 150$ and L/100, respectively.

Although the Young's modulus of basalt and glass fibres is significantly lower than for carbon fibres, the experimental flexural toughness of specimens V-BR3-01 and V-GPHDM-02 was higher than the equivalent beams strengthened with CXM25. This might be due to the lack of adherence between the carbon textiles and the cementitious matrix, as was also noted by Bernat et al. [10]. These results suggest that the adhesion between the concrete and the TRM is an important factor that can determine the flexural toughness and the failure mechanism of TRM strengthened beams.

\section{Bonding behaviour}

To validate the proposed method, the experimental $\left(\Delta \gamma_{x y-S G}\right)$ and theoretical $\left(\Delta \gamma_{x y-E Q}\right)$ shear strain increments of the control beam were compared. The theoretical behaviour accurately represented the experimental behaviour before cracking. However, there was a decrement of the experimental shear strain curve, which might be caused by the crack opening. In contrast, the theoretical curve behaved linearly up to failure. These results suggest that the proposed method is valid for comparing the bonding behaviour of TRM strengthening before cracking of the concrete.

As observed in Figure 10a and Figure 10d, the specimens strengthened with glass and basalt textiles showed the highest adhesion with the concrete substrate. On the other hand, carbon textiles showed the highest scattering of the bonding experimental results (Figure 10b). This fact is in accordance with the evidence found in the shear resistance and flexural toughness analyses. Finally, a lower scattering of the results was obtained with specimens strengthened with PBO textiles (Figure 10c). In these cases, the experimental shear strains of the TRM were significantly lower than theoretical shear strain due to the limited bonding capacity of the mortar XM750 related to this type of fabric. 
Taking into account the mortar properties in the analysis (Table 2), it can be observed that the strengthening cases whose matrices have higher bond strength developed higher adherence performance during the loading process. Moreover, some of the investigated strengthening systems showed a deficient adhesion between the mortar and the concrete substrate and/or between the textile and the mortar matrix. Despite the limited tests carried out, it was observed that the mechanical capacity of the TRM strengthening system and the global behaviour of the strengthened structure tended to be limited by this phenomenon.

\section{Analytical study}

The following subsections describe the calculation methodologies included in the design codes for TRM and FRP used as shear strengthening materials. These analytical models are considered to study the prediction of the ultimate shear resistance of the tested beams and to compare it with the obtained experimental results. In the case of the FRP-strengthening models, the formulation is adapted to TRM reinforcement characteristics.

\subsection{Studied codes}

fib-Bulletin 14 model

The proposed model by fib-Bulletin 14 [23] is applicable to RC beams externally strengthened with FRP. This model is based on the assumption that the different strengthening parts that compound the beam separately contribute to the ultimate shear resistance of the specimen $\left(V_{R}\right)$ (Eq. 3).

$$
V_{R}=V_{c}+V_{s}+V_{f} \quad \text { Eq. } 3
$$

where $V_{c}, V_{s}$ and $V_{f}$ are the shear contributions of the concrete, the steel stirrups and the FRP reinforcement, respectively. According to this model, the shear contribution provided by $\operatorname{FRP}\left(V_{f, f i b 14}\right)$ is defined as (Eq. 4):

$$
V_{f, f i b 14}=0,9 \varepsilon_{f, e} E_{f u} \rho_{f} b_{w} d(\cot \alpha+\cot \theta) \sin \alpha \quad \text { Eq. } 4
$$

where $\varepsilon_{f, e}$ is the effective strain of FRP in the principal reinforcement direction, $E_{f u}$ is the longitudinal elastic modulus of FRP, $\rho_{f}$ is the FRP reinforcement ratio, $b_{w}$ and $d$ are the width and the effective depth of the RC beam cross section, respectively, and $\alpha$ and $\theta$ are the angle between the main direction of the fibres and the longitudinal axis of the beam and the angle between the diagonal crack and the longitudinal axis of the beam, respectively.

The effective strain in the principal direction of reinforcement $\varepsilon_{f, e}$ is, in general, lower than the ultimate strain of FRP $\varepsilon_{f u}$ and adopts different expressions depending on the failure mode, the type of the FRP fibre and the reinforcement wrapping configuration [36,37].

\section{ACl 440.2R-08 model}

The model proposed by ACl 440.2R-08 [24] defines the nominal shear resistance of the structural element as the addition of the contributions of the different parts involved in bearing the shear stresses (Eq. 3). In this case, the shear contribution provided by FRP reinforcement $\left(V_{f, A C I 440}\right)$ is calculated according to Eq. 5 :

$$
V_{f, A C I 440}=\frac{A_{f v} \varepsilon_{f, e} E_{f u}(\sin \alpha+\cos \alpha) d_{f v}}{S_{f}} \quad \text { Eq. } 5
$$


where $A_{f v}$ is the area of FRP reinforcement, $\varepsilon_{f, e}$ is the effective strain of FRP in the principal reinforcement direction, $E_{f u}$ is the longitudinal elastic modulus of FRP, $d_{f v}$ is the effective depth of shear reinforcement, $s_{f}$ is the span between FRP laminates or sheets (in the case of continuous reinforcement, this parameter equals the reinforcement width and does not influence the formulation), and $\alpha$ is the angle between the principal direction of the fibres and the longitudinal axis of the beam.

The effective strain in the principal direction of reinforcement $\varepsilon_{f, e}$ is a parameter that mainly depends on the reinforcement-wrapping configuration, i.e., full wrapping, U-shaped jacketing or side bonding. In the case of the last two configurations, the effective strain $\varepsilon_{f, e}$ is obtained by reducing the ultimate strain of FRP $\varepsilon_{f u}$ using the bond-dependent coefficient for shear $\kappa_{v}$. This parameter mainly depends on geometric variables and the concrete and FRP mechanical properties.

\section{ACl 549.4R-13 model}

ACl 549.4R-13 [22] is the first model that addresses RC structures externally strengthened with cementitious matrix composite materials, i.e., TRM. The nominal shear resistance of the structural strengthened element follows the same expression defined in Eq. 3. The TRM reinforcement contribution to the shear resistance $\left(V_{f, A C I 549}\right)$ adopts the following expression (Eq. 6):

$$
V_{f, A C I 549}=n A_{f} \varepsilon_{f v} E_{f} d_{f v} \quad \text { Eq. } 6
$$

where $n$ is the number of textile layers applied in the reinforcement, $A_{f}$ is the area of mesh reinforcement by unit width, $\varepsilon_{f v}$ is the design tensile strain of TRM shear reinforcement, $E_{f}$ is the tensile modulus of elasticity of cracked TRM, and $d_{f v}$ is the effective depth of TRM shear reinforcement. In this study case, $\varepsilon_{f v}$ is considered to be equivalent to the ultimate tensile strain of TRM $\left(\varepsilon_{f u, T R M}\right)$. The limitation of 0.004 is not taken into account because it is a design limitation.

In contrast with the previous two models, this code poses an analytic development using the mechanical properties of TRM. This approach is logical and feasible, but it presents serious calculation difficulties because most manufacturers do not provide the mechanical properties of composite materials but provide the mechanical properties of the fibres that compound the fabric. To overcome this issue, a summary of the mechanical properties of two types of TRM reinforcement is included in the model.

This analytical approach also presents difficulties when different manufacturers provide components of TRM. In this case, material characterization tests are required to predict the reinforcement shear resistance. The lack of standardized criteria to obtain the mechanical properties of TRM complicates the design and calculation process.

Finally, in the case of bidirectional meshes, the contribution to the shear reinforcement strength of the secondary textile tows is considered in ACI 549.4R-13 [22]. In the present study, only the contribution of the tows perpendicularly arranged to the longitudinal axis of the beam have been taken into account to obtain results that can be directly comparable with other design codes.

\subsection{Particularities of the analysis}


With the aim of adapting the formulae proposed by fib-Bulletin 14 [23] and ACl 440.2R-08 [24] to calculate the shear contribution provided by TRM reinforcement, the following facts are considered:

- In both cases, the expressions of effective strain $\varepsilon_{f, e}$ derived from U-shaped jacket wrapping configuration are used.

- In the case of fib-Bulletin 14 [23], the expression of effective strain $\varepsilon_{f, e}$ for CFRP (carbon fibrereinforced polymer) reinforcement is used, taking into account a failure mode based on the reinforcement fracture and discarding the included expression used for peeling-off failures.

- An equivalent uniform distribution of textile fibres along the reinforcement width is considered.

- Mechanical properties of fibres $\left(E_{f i b}\right.$ and $\left.\varepsilon_{f i b}\right)$ provided by the manufacturers are considered (Table 3 ).

In the case of the predictions of shear resistance provided by TRM according to ACI 549.4R-13 [22], TRM properties included in Table 5 are used.

The experimental shear contributions of the studied TRM reinforcements $\left(V_{f, \text { exp }, j, i}\right)$ have been obtained by subtracting the concrete shear resistance obtained according to the standard Eurocode 2 [35] $\left(V_{c, E C 2}\right)$ or the standard $\mathrm{ACl} 318$ [38] $\left(V_{c, A C \mid 118}\right)$ from the ultimate shear resistance developed by $\mathrm{RC}$ beams strengthened with a particular type of TRM $\left(V_{u, \text { exp, }, i}\right)$ (Table 6$)$. In the case of the existing two samples with the same TRM reinforcement, the results are the average between them (Eq. 7 and Eq. 8).

$$
\begin{aligned}
V_{f, \exp , E C 2, i}= & \frac{\sum_{0}^{n_{i}} V_{u, \exp , i}}{n_{i}}-V_{c, E C 2} \\
V_{f, \exp , A C I 318, i}=\frac{\sum_{0}^{n_{i}} V_{u, \exp , i}}{n_{i}}-V_{c, A C I 318} & \text { Eq. } 7
\end{aligned}
$$

where $n_{i}$ is the number of samples for each TRM reinforcement studied, and $i$ corresponds to each type of TRM reinforcement. It is important to highlight that in the case of specimens that developed failure mode $A$ (see Figure 6), the experimental shear resistance values provided by TRM represent a lower threshold value because failure did not occur in the area strengthened with TRM.

\subsection{Results and comparison}

Figure 11 shows the different contributions of TRM to the shear resistance. Table 7 summarises the relative errors between the experimental contributions of TRM $V_{f, \text { exp,i }}$ (defined as the average values of $V_{f, e x p, E C 2, i}$ and $\left.V_{f, e x p, A C \mid 318, i}\right)$ and the analytical predictions according to the considerations described above. 


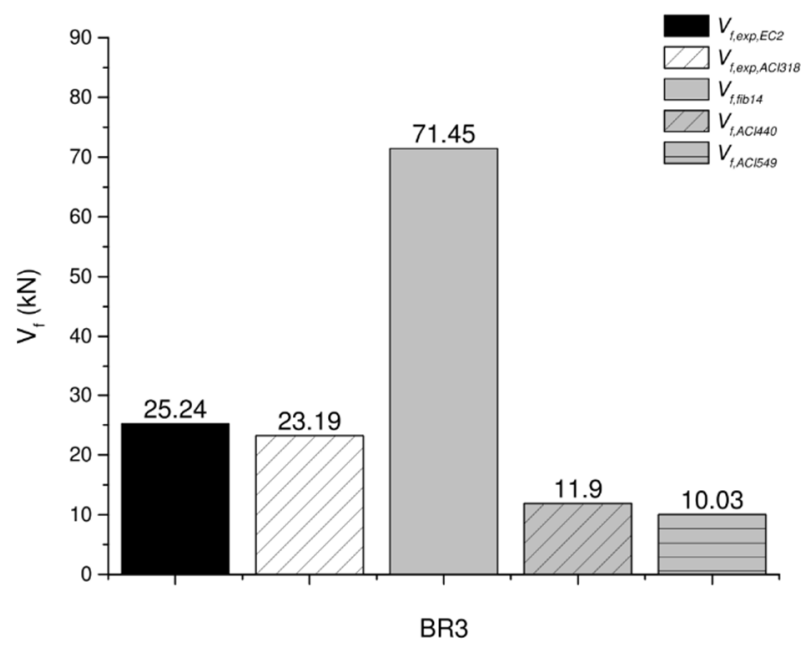

(a)

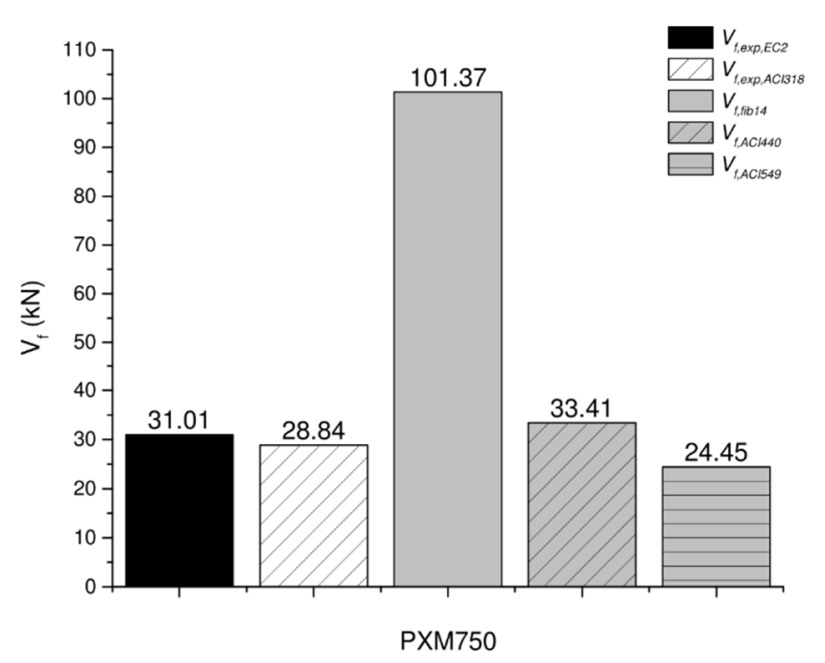

(c)

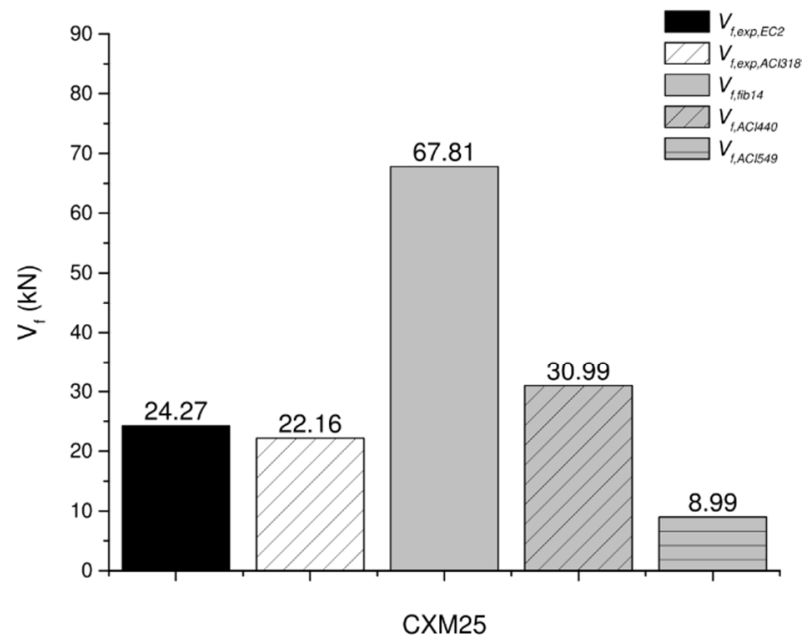

(b)

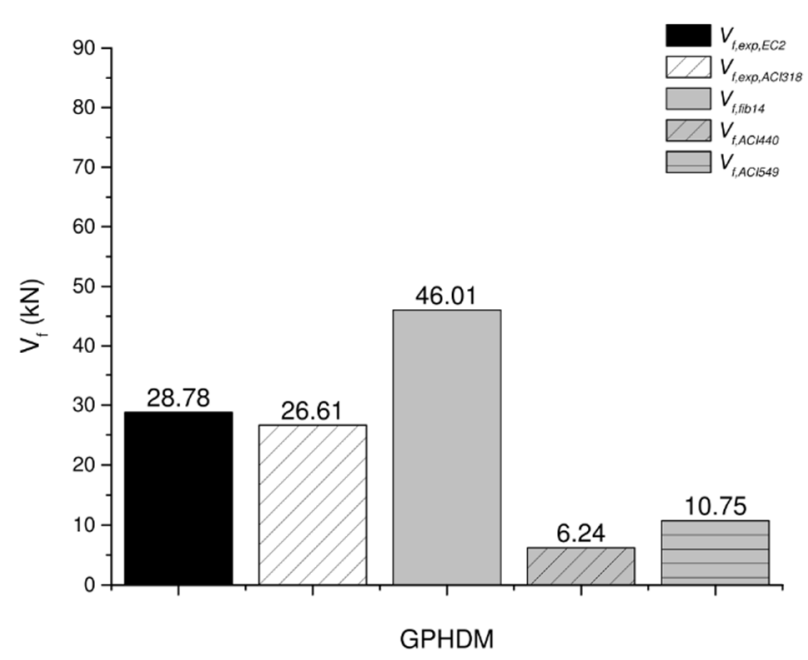

(d)

Figure 11. Experimental and analytical shear resistance contributions of the TRM reinforcements: (a) BR3, (b) CXM25, (c) PXM750 and (d) GPHDM.

Table 7. Relative error between the experimental results and the analytical predictions of the shear resistance contribution provided by the TRM reinforcements (absolute values).

\begin{tabular}{ccccc}
\hline & BR3 & CXM25 & PXM750 & GPHDM \\
\hline$\varepsilon\left(V_{f, \exp }-V_{f, f i b 14}\right)(\%)$ & 195.07 & 192.10 & 238.75 & 66.09 \\
$\varepsilon\left(V_{f, \exp }-V_{f, A C 1440}\right)(\%)$ & 50.86 & 33.49 & 11.65 & 77.47 \\
$\varepsilon\left(V_{f, \exp }-V_{f, A C 1549}\right)(\%)$ & 58.58 & 61.28 & 18.30 & 61.18 \\
\hline
\end{tabular}

Prior to discussing the prediction capacities of the previously analysed models, it is important to note that the experimental shear contributions of the reinforcements obtained using the shear resistance of the concrete according to Eurocode 2 [35] $\left(V_{f, e x p, E C 2, i}\right)$ were between $7.5 \%$ and $9.5 \%$ higher than those analogously calculated with the shear resistance of the concrete in accordance with $\mathrm{ACl} 318$ [38] $\left(V_{f, e x p, A C I 138, i}\right)$ (Figure 11). This difference does not seem relevant in comparison with the variations obtained 11 in the following comparative analysis. 
As can be observed in Figure 11 and as a general trend, the shear resistance contributions of TRM, which were obtained using the fib-Bulletin 14 [23] formulation, overestimate the test results. On the other hand, the results obtained according to $\mathrm{ACl} 549.4 \mathrm{R}-13$ [22] underestimate the experimental values in all cases.

Regarding the individual analysis of the different TRM combinations, in the case of basalt textile reinforcement (Figure 11a), the obtained value using fib-Bulletin 14 [23] exceeds 195\% of the experimental results (Table 7). By contrast, the results obtained with this TRM reinforcement in accordance with $\mathrm{ACl}$ 440.2R-08 [24] and ACl 549.4R-13 [22] are conservative. This trend is similar in the case of glass textile reinforcement (Figure 11d), considering that $\mathrm{ACl} 440.2 \mathrm{R}-08$ [24] is highly conservative.

Figure $11 \mathrm{~b}$ shows the results obtained with carbon textiles TRM. Herein, the value obtained with $\mathrm{ACl}$ 549.4R-13 [22] is considerably lower than the obtained with ACl 440.2R-08 [24], which indicates a much better performance in accordance with the experimental results.

Finally, it is important to outline that the TRM experimental results of the PBO textile reinforcement (Figure 11c) are those that best meet the analytical predictions according to the $\mathrm{ACl}$ models. By contrast, the analytical prediction using the fib-Bulletin 14 [23] model is notably different from the other values at over three times higher with respect to the experimental results (Table 7).

\section{Improvements to the existing analytical method}

In this section, an analytical formulation is presented based on the experimental results of the current research and similar studies from other researchers $[12,13,17]$. This analytical tool is aimed to complement the analytical model proposed by Triantafillou and Papanicolaou [12] by providing an accurate

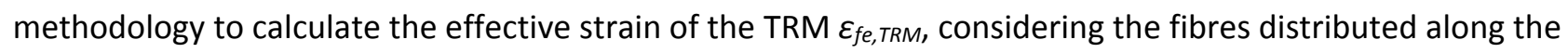
main direction of the mesh.

\subsection{Procedure}

Because there is not enough significant information about the mechanical properties of TRM and the corresponding characterization methods, the proposed analytical tool is based on the following: a) the experimental results from tests on TRM shear strengthened RC beams and $b$ ) the mechanical properties of the fibres that compose the strengthening textiles.

Thus, when assuming that the strengthening system is applied according to the methodologies that prevent the debonding failure [15] and taking into account only the contribution of those fibres arranged perpendicular to the beam axis, the contribution of TRM to the shear resistance $\left(V_{f}\right)$ can be determined using (Eq. 9):

$$
V_{f}=2 n \varepsilon_{f e, T R M} E_{f i b} t_{t e x} d_{f v}(\cot \alpha+\cot \theta) \sin ^{2}(\alpha) \quad \text { Eq. } 9
$$

where $n$ is the number of the textiles applied to the strengthening, $\varepsilon_{f e, T R M}$ is the effective strain of TRM when only the fibres distributed along the main direction of the mesh are taken into account, $E_{f i b}$ is the longitudinal elasticity modulus of the textile fibres, $t_{t e x}$ is the textile equivalent thickness, $d_{f v}$ is the effective shear reinforcement depth, and $\alpha$ and $\theta$ are the angles between the main direction of the fibres and the longitudinal axis of the beam and the angle between the diagonal crack and the longitudinal axis of the beam, respectively. 
1 The equivalent thickness of the textile $\left(t_{\text {tex }}\right)$ is a parameter usually provided by the manufacturer. It relates

2 the thickness of the grid with the geometrical distribution of the fibres and can be calculated as follows

3 (Eq.10):

$$
t_{t e x}=\frac{a}{s} t
$$

4

where $t$ is the thickness of the grid, $a$ is the width of the tow, and $s$ is the distance between two consecutive tows (from axis to axis).

To calculate the effective strain of the TRM, the new potential law shown in (Eq. 11), which is based on the research by Triantafillou and Antonopoulus [37] on FRP shear strengthening, is proposed and adjusted:

$$
\varepsilon_{f e, T R M}=A\left(\frac{f_{c m}^{2 / 3}}{E_{f i b} \rho_{t e x}}\right)^{B} \varepsilon_{f i b} \quad \text { Eq. } 11
$$

where $f_{c m}$ is the average compressive strength of the concrete, $E_{f i b}$ and $\varepsilon_{f i b}$ are the longitudinal elasticity modulus and the ultimate strain of the fibres of the textile, respectively, and $\rho_{\text {tex }}$ is the reinforcement ratio of the strengthening fabric, which is calculated according to (Eq. 12):

$$
\rho_{\text {tex }}=\frac{2 n t_{t e x} \sin (\alpha)}{b_{w}}
$$

where $b_{w}$ is the width of the concrete cross section.

\subsection{Results}

With the aim of obtaining accurate values for parameters $A$ and $B$, which are required in Eq. 11 , the study samples were extended by including the results obtained by Triantafillou and Papanicolaou [12], Blanksvärd et al. [13] and Al-Salloum et al. [17] in research characterised by the fact that the specimens avoided the debonding failure of the TRM. Table 8 shows a summary of the data that were used for the developed analytical model. The contribution of the TRM reinforcement to the shear resistance was obtained by subtracting the shear resistance of the concrete, which was calculated according to Eurocode 2 [35], from the experimental shear resistance using Eq. 7. It has to be noted that the cracking angle value with respect to the longitudinal axis of the beam $(\theta)$ was set to $45^{\circ}$ for those cases that do not specify this variable. The effective strain of the TRM $\left(\varepsilon_{f e, \text { TRM }}\right)$ was calculated using the required experimental data by isolating this variable from Eq. 9. 
Table 8. Experimental data on the shear strengthening of RC beams with TRM.

\begin{tabular}{|c|c|c|c|c|c|c|c|c|c|c|c|c|c|}
\hline Specimen & Textile & $\begin{array}{l}\text { Strengthening } \\
\text { configuration }^{+}\end{array}$ & $\begin{array}{c}V_{f} \\
(k N)\end{array}$ & $\begin{array}{l}\varepsilon_{f i b} \\
(\%)\end{array}$ & $\begin{array}{c}E_{f i b} \\
(G P a)\end{array}$ & $n$ & $\begin{array}{c}t_{\text {tex }} \\
(\mathrm{mm})\end{array}$ & $\begin{array}{c}d_{f v} \\
(m m)\end{array}$ & $\begin{array}{l}\alpha \\
\left({ }^{\circ}\right)\end{array}$ & $\begin{array}{c}\theta \\
\left({ }^{\circ}\right)\end{array}$ & $\begin{array}{c}\varepsilon_{f e, T R M} \\
(\%)\end{array}$ & $\begin{array}{c}f_{c m} \\
(\mathrm{MPa})\end{array}$ & $\begin{array}{c}b_{w} \\
(m m)\end{array}$ \\
\hline$V-B R 3-01$ & B & $U$ & 25.24 & 3.15 & 95 & 1 & 0.0530 & 239 & 90 & 44 & 1.01 & 33.78 & 300 \\
\hline$V-C X M 25-01$ & C & $U$ & 29.63 & 1.80 & 240 & 1 & 0.0470 & 239 & 90 & 38 & 0.43 & 33.78 & 300 \\
\hline$V-C X M 25-02$ & C & $U$ & 18.91 & 1.80 & 240 & 1 & 0.0470 & 239 & 90 & 56 & 0.52 & 34.07 & 300 \\
\hline$V-P X M 750-01$ & $\mathrm{P}$ & $U$ & 27.34 & 2.15 & 270 & 1 & 0.0455 & 239 & 90 & 42 & 0.42 & 34.07 & 300 \\
\hline$V-P X M 750-02$ & $\mathrm{P}$ & $U$ & 34.67 & 2.15 & 270 & 1 & 0.0455 & 239 & 90 & 40 & 0.50 & 34.07 & 300 \\
\hline V-GPHDM-02 & G & $U$ & 28.78 & 2.90 & 90 & 1 & 0.0420 & 239 & 90 & 46 & 1.65 & 34.07 & 300 \\
\hline$M 1^{(1)}$ & C & W & 46.98 & 1.49 & 225 & 1 & 0.0470 & 244.8 & 90 & 45 & 0.91 & 30.50 & 150 \\
\hline$M 2^{(1)}$ & C & w & 68.83 & 1.49 & 225 & 2 & 0.0470 & 244.8 & 90 & 45 & 0.66 & 30.50 & 150 \\
\hline$M 2 s^{(1)}$ & C & W & 65.78 & 1.49 & 225 & 2 & 0.0470 & 244.8 & 80 & 45 & 0.56 & 30.50 & 150 \\
\hline C4OsO-M2-G1(2) & C & $S$ & 78.27 & 1.50 & 234 & 1 & 0.0245 & 381.6 & 90 & 34 & 1.21 & 55.70 & 180 \\
\hline C4OSO-M2-G2a & C & S & 115.07 & 1.50 & 234 & 1 & 0.0459 & 381.6 & 90 & 36 & 1.02 & 55.70 & 180 \\
\hline C4OSO-M2-G2 $b^{(2)}$ & C & $S$ & 112.07 & 1.50 & 234 & 1 & 0.0459 & 381.6 & 90 & 32 & 0.85 & 55.70 & 180 \\
\hline C4OsO-M3-G2(2) & C & $S$ & 105.27 & 1.50 & 234 & 1 & 0.0459 & 381.6 & 90 & 34 & 0.87 & 55.70 & 180 \\
\hline C4OSO-M2-G2(2) & C & $S$ & 122.07 & 1.50 & 234 & 1 & 0.0459 & 381.6 & 90 & 34 & 1.00 & 55.70 & 180 \\
\hline C4OsO-M2-G3(2) & C & $S$ & 76.57 & 1.50 & 234 & 1 & 0.0330 & 381.6 & 90 & 31 & 0.78 & 55.70 & 180 \\
\hline C4OsO-M1-G3(2) & C & s & 50.27 & 1.50 & 234 & 1 & 0.0330 & 381.6 & 90 & 31 & 0.51 & 55.70 & 180 \\
\hline$B S 2^{(3)}$ & B & $S$ & 15.53 & 1.95 & 31.94 & 2 & 0.0640 & 148.5 & 90 & 45 & 1.28 & 20.00 & 150 \\
\hline$B S 3^{(3)}$ & B & S & 15.96 & 1.95 & 31.94 & 2 & 0.0640 & 148.5 & 45 & 45 & 1.31 & 20.00 & 150 \\
\hline$B S 4^{(3)}$ & B & $S$ & 18.57 & 1.95 & 31.94 & 4 & 0.0640 & 148.5 & 90 & 45 & 0.76 & 20.00 & 150 \\
\hline$B S 5^{(3)}$ & B & S & 20.47 & 1.95 & 31.94 & 4 & 0.0640 & 148.5 & 45 & 45 & 0.84 & 20.00 & 150 \\
\hline$B S 6^{(3)}$ & B & S & 15.89 & 1.95 & 31.94 & 2 & 0.0640 & 148.5 & 90 & 45 & 1.31 & 20.00 & 150 \\
\hline$B S 7^{(3)}$ & B & $S$ & 15.89 & 1.95 & 31.94 & 2 & 0.0640 & 148.5 & 45 & 45 & 1.31 & 20.00 & 150 \\
\hline$B S 8^{(3)}$ & B & s & 22.33 & 1.95 & 31.94 & 4 & 0.0640 & 148.5 & 90 & 45 & 0.92 & 20.00 & 150 \\
\hline$B S 9^{(3)}$ & B & $\mathrm{s}$ & 31.25 & 1.95 & 31.94 & 4 & 0.0640 & 148.5 & 45 & 45 & 1.29 & 20.00 & 150 \\
\hline
\end{tabular}

(1) Triantafillou and Papanicolaou [12].

(2) Blanksvärd et al. [13].

(3) Al-Salloum et al. [17].

${ }^{*} \mathrm{~B}=$ Basalt; $\mathrm{C}=$ Carbon; $\mathrm{P}=\mathrm{PBO} ; \mathrm{G}=$ Glass.

${ }^{+} \mathrm{W}=$ Fully wrapped; $\mathrm{U}=\mathrm{U}$-shaped jacket; $\mathrm{S}=$ Side bonded.

1

2 Figure 12 shows the experimental results included in Table 8, plotting the standardised strain of the TRM,

$3 \varepsilon_{f e, T R M} / \varepsilon_{f i b}$, versus the variable $E_{f i b} \rho_{t e x} / f_{c m}^{2 / 3}$. Two response curves, which are based on Eq. 11 , are

4 shown in this figure. One curve (the $\mathrm{W}$ curve) corresponds to the fully wrapped configuration, and the

5 other curve (the U \& S curve) corresponds to side bonded or U-shaped jacket strengthening configurations.

6 The values of the parameters of the potential law, A and B, used to calculate these curves are summarised

7 in Table 9. 


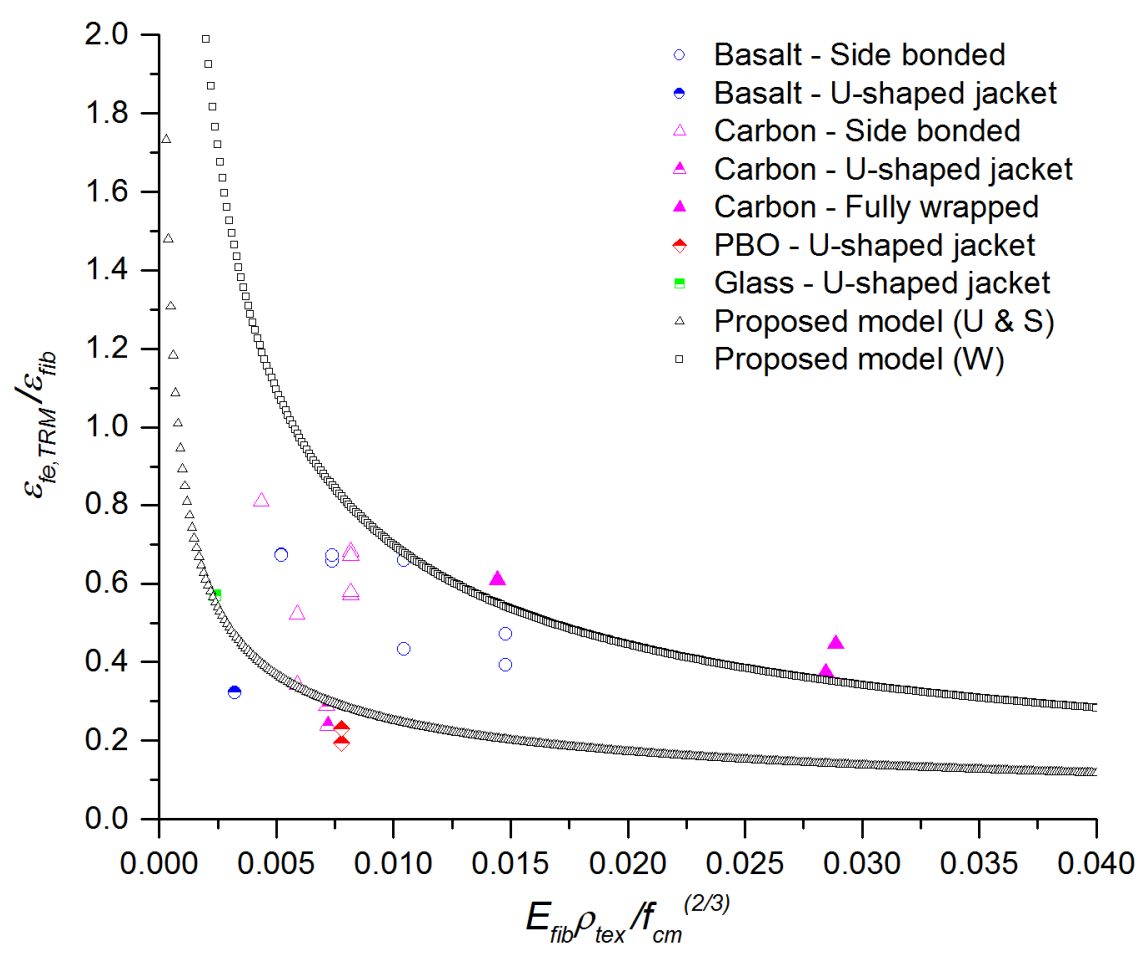

Figure 12. TRM normalized strain $\varepsilon_{f e, T R M} / \varepsilon_{f i b}$ Vs. $E_{f i b} \rho_{t e x} / f_{c m}^{(2 / 3)}$

Table 9. $A$ and $B$ values related to the strengthening configuration of the reinforcement.

\begin{tabular}{lcc}
\multicolumn{1}{c}{$\begin{array}{c}\text { Strengthening } \\
\text { configuration }\end{array}$} & $\boldsymbol{A}$ & $\boldsymbol{B}$ \\
\hline $\begin{array}{l}\text { Fully wrapped (W) } \\
\text { Side bonded (S) or U-shaped } \\
\text { jacket (U) }\end{array}$ & 0.035 & 0.65 \\
& 0.020 & 0.55 \\
\hline
\end{tabular}

5 Finally, and taking into account the experimental data gathered to date, the proposed formulation to

6 calculate the effective strain of the TRM $\left(\varepsilon_{f e, T R M}\right)$ when it is applied as a shear strengthening system and the 7 debonding failure is avoided is presented in Eq. 13 and Eq. 14, depending on the strengthening

8 configuration: - Fully wrapped:

$$
\varepsilon_{f e, T R M}=0,035\left(\frac{f_{c m}^{2 / 3}}{E_{f i b} \rho_{t e x}}\right)^{0,65} \varepsilon_{f i b}
$$


- Side bonded or U-shaped jacket:

$$
\varepsilon_{f e, T R M}=0,020\left(\frac{f_{c m}^{2 / 3}}{E_{f i b} \rho_{t e x}}\right)^{0,55} \varepsilon_{f i b}
$$

It is important to note that $E_{f i b}$ and $f_{c m}$ are expressed in GPa and $\mathrm{MPa}$, respectively, for previous equations and figures.

\subsection{Discussion}

Observing Figure 12, it can be noticed that the TRM standardised strain decreases as the term $E_{f i b} \rho_{t e x} / f_{c m}^{2 / 3}$ increases. The proposed curve for side bonded or U-shaped jacket configurations shows a conservative trend in comparison with the experimental results from Blanksvärd et al. [13] and Al-Salloum et al. [17], who used carbon and basalt textiles to laterally shear strengthen RC beams, respectively. In contrast, this curve overestimates the experimental results of the U-shaped jacket configuration because it considers that the experimental data are only a lower threshold value for the contribution of the TRM to the shear resistance for most of the cases.

For the beams strengthened with TRM applied in a fully wrapped configuration, the proposed curve accurately adjusts the experimental values, although these are not numerous and only one type of TRM has been considered.

The analytical expressions, which define the previously described curves, might change in the future when additional experimental data become available.

\section{Conclusions}

This research studies the structural response of RC beams shear strengthened with different types of TRM. An experimental approach compares the performance of various strengthening systems. In addition, the effectiveness of these strengthening systems to increase the flexural toughness of the specimens is analysed, and a new methodology to study the bonding performance of TRM is presented.

The different TRM combinations allow a significant increase in the ultimate shear resistance of the RC beams, reaching an average load-bearing rise of $36 \%$. Moreover, all of the strengthened beams showed a remarkable increase in flexural toughness. Ductile failure was a noticeable improvement in comparison with the brittle failure of the unstrengthened beams.

The results suggest that the effectiveness of the strengthening systems is limited by the bonding performance of the matrix of the TRM with the concrete substrate and/or with the reinforcing textile. Experiments confirm that TRM debonding failure is prevented when TRM application follows the methodology proposed by Brückner et al. [15].

Regarding the comparison among the different TRM combinations, it can be said that PBO textiles (PXM750) showed the best performance, increasing the shear resistance and flexural toughness of the strengthened beams, even in the non-linear stage. However, it was the less-effective system when comparing the ratio between the mechanical properties and bonding response. TRM of basalt fibres (BR3) and glass fibres (GPHDM) developed a similar shear structural response achieving more efficient results. Moreover, both TRM reinforcements provided a similar increase in absorbed energy prior to the collapse of 
1 the specimens. Concerning the bonding performance, glass fibre reinforcement showed better

2 performance than basalt fibre TRM.

3 On the other hand, TRM with carbon fibres (CXM25) performed very irregularly, with a great scattering of

4 the experimental results. This behaviour was likely due to a limited adherence between the mortar and

5 textile [10]. The beams strengthened with TRM carbon fibres did not develop ductile failure; however, they

6 developed an average shear capacity increase of $22 \%$.

7 Analytic approaches with standards based on the FRP technology (and ACl 440.2R-08 [24]) and TRM

8 strengthening system ( $\mathrm{ACl}$ 549.4R-13 [22]) have been carried out. It is noted that while the predictions

9 using fib-Bulletin 14 [23] highly overestimate the experimental results, the contributions to the shear

10 resistance provided by TRM using ACI 549.4R-13 [22] formulae show a conservative tendency. Although ACl

$11440.2 \mathrm{R}-08$ [24] is a code for the design of RC beams externally strengthened with FRP, it reached the best

12 accuracy at predicting the contribution of the TRM to the shear resistance.

13 This work proposed an analytical method to estimate TRM contribution to the shear capacity. This method 14 is based on the TRM effective strain concept $\left(\varepsilon_{f e, T R M}\right)$. Depending on the configuration of the applied TRM,

15 a) fully wrapped or b) side bonded or U-shaped jacket, two potential laws have been defined to obtain this 16 effective strain. These potential laws depend on the geometric distribution of the fibres in the textiles, the 17 mechanical properties of the fibres and the compressive strength of the concrete. Potential laws fitted the 18 experimental results from tests carried out both in this study and by other authors.

19 Finally, further research is necessary to better adjust the TRM response when it is used as a shear 20 strengthening system. Moreover, it is necessary to study failure prediction due to debonding between the 21 mortars and the concrete substrate and between the matrix and the textile of the TRM. 


\section{References}

[1] S. Rostam, R.F.M. Bakker, A.W. Beeby, D. van Nieuwenburg, P. Schiessl, L. Sentler, et al., Durable Concrete Structures - CEB Design Guide, 2nd ed., Thomas Telford Ltd, Lausanne, Switzerland, 1992.

[2] H.K. Cheong, N. MacAlevey, Experimental behavior of jacketed reinforced concrete beams, Journal of Structural Engineering. (2000) 692-699.

[3] A. Sharif, G.J. Al-Sulaimani, I.A. Basunbul, M.H. Baluch, M. Husain, Strengthening of shear-damaged RC beams by external bonding of steel plates, Magazine of Concrete Research. 47 (1995) 329-334.

[4] B.B. Adhikary, H. Mutsuyoshi, M. Sano, Shear strengthening of reinforced concrete beams using steel plates bonded on beam web: experiments and analysis, Construction and Building Materials. 14 (2000) 237-244.

[5] S.S. Pendhari, T. Kant, Y.M. Desai, Application of polymer composites in civil construction: A general review, Composite Structures. 84 (2008) 114-124.

[6] T.C. Triantafillou, C.G. Papanicolaou, Textile reinforced mortars (TRM) versus fibre reinforced polymers (FRP) as strengthening materials of concrete structures, in: Proceedings of the 7th ACl International Symposium on Fibre-Reinforced (FRP) Polymer Reinforcement for Concrete Structures, 2005: pp. 99-118.

[7] W. Brameshuber, T. Brockmann, C. Aldea, T. Gries, A. Roye, P. Offermann, et al., Textile Reinforced Concrete. State-of-the-Art Report of RILEM TC 201-TRC, Report 36, RILEM Publications S.A.R.L., Bagneux, 2006.

[8] C.G. Papanicolaou, T.C. Triantafillou, K. Karlos, M. Papathanasiou, Textile-reinforced mortar (TRM) versus FRP as strengthening material of URM walls: in-plane cyclic loading, Materials and Structures. 40 (2006) 1081-1097.

[9] C.G. Papanicolaou, T.C. Triantafillou, M. Papathanasiou, K. Karlos, Textile reinforced mortar (TRM) versus FRP as strengthening material of URM walls: out-of-plane cyclic loading, Materials and Structures. 41 (2007) 143-157.

[10] E. Bernat, L. Gil, P. Roca, C. Escrig, Experimental and analytical study of TRM strengthened brickwork walls under eccentric compressive loading, Construction and Building Materials. 44 (2013) 35-47.

[11] L. Garmendia, J.T. San-José, D. García, P. Larrinaga, Rehabilitation of masonry arches with compatible advanced composite material, Construction and Building Materials. 25 (2011) 43744385.

[12] T.C. Triantafillou, C.G. Papanicolaou, Shear strengthening of reinforced concrete members with textile reinforced mortar (TRM) jackets, Materials and Structures. 39 (2006) 93-103.

[13] T. Blanksvärd, B. Täljsten, A. Carolin, Shear Strengthening of Concrete Structures with the Use of Mineral-Based Composites, Journal of Composites for Construction. 13 (2009) 25-34.

[14] Y.A. Al-Salloum, N.A. Siddiqui, H.M. Elsanadedy, A.A. Abadel, M.A. Aqel, Textile-reinforced mortar versus FRP as strengthening material for seismically deficient RC beam-column joints, Journal of Composites for Construction. 15 (2011) 920-933. 
[15] A. Brückner, R. Ortlepp, M. Curbach, Textile reinforced concrete for strengthening in bending and shear, Materials and Structures. 39 (2006) 741-748.

[16] A. Brückner, R. Ortlepp, M. Curbach, Anchoring of shear strengthening for T-beams made of textile reinforced concrete (TRC), Materials and Structures. 41 (2007) 407-418.

[17] Y.A. Al-Salloum, H.M. Elsanadedy, S.H. Alsayed, R.A. Iqbal, Experimental and numerical study for the shear strengthening of reinforced concrete beams using Textile-Reinforced Mortar, Journal of Composites for Construction. 16 (2012) 74-90.

[18] R. Azam, K. Soudki, FRCM Strengthening of Shear-Critical RC Beams, Journal of Composites for Construction. 18 (2014).

[19] E. Tzoura, T.C. Triantafillou, Shear strengthening of reinforced concrete T-beams under cyclic loading with TRM or FRP jackets, Materials and Structures. (2014).

[20] A. Si Larbi, R. Contamine, E. Ferrier, P. Hamelin, Shear strengthening of RC beams with textile reinforced concrete (TRC) plate, Construction and Building Materials. 24 (2010) 1928-1936.

[21] R. Contamine, A. Si Larbi, P. Hamelin, Identifying the contributing mechanisms of textile reinforced concrete (TRC) in the case of shear repairing damaged and reinforced concrete beams, Engineering Structures. 46 (2013) 447-458.

[22] ACl Committee 549, ACl 549.4R-13 - Guide to Design and Construction of Externally Bonded FabricReinforced Cementitious Matrix (FRCM) Systems for Repair and Strengthening Concrete and Masonry Structures, (2013).

[23] Fédération Internationale du Betón, fib-Bulletin 14. Externally Bonded FRP Reinforcement for RC Structures, (2001).

[24] $\mathrm{ACl}$ Committee 440, ACl 440.2R-08 - Guide for the Design and Construction of Externally Bonded FRP Systems, (2008).

[25] P. Larrinaga, J.T. San-José, D. García, L. Garmendia, J. Díez, Experimental study of the flexural behaviour of low performance RC beams strengthened with textile reinforced mortar, in: International Rilem Conference on Material Science and 64th RILEM Annual Week in Aachen MATSCI 1. 75, 2010: pp. 235-244.

[26] L. Gil, C. Escrig, E. Bernat, Bending performance of concrete beams strengthened with textile reinforced mortar TRM, Key Engineering Materials. 601 (2014) 203-206.

[27] Comité Européen de Normalisation, EN 12390-1. Testing hardened concrete - Part 1: Shape, dimensions and other requirements for specimens and moulds, (2012).

[28] Comité Européen de Normalisation, EN 12390-3. Testing hardened concrete - Part 3: Compressive strength of test specimens, (2009).

[29] Comité Européen de Normalisation, EN ISO 15630-1. Steel for the reinforcement and prestressing of concrete. Test methods - Part 1: Reinforcing bars, wire rod and wire, (2010).

[30] Comité Européen de Normalisation, EN 1015-11. Methods of test for mortar for masonry - Part 11: Determination of flexural and compressive strength of hardened mortar, (1999). 
1 [31] E. Bernat, Analysis of unreinforced and TRM-strengthened brickwork walls with eccentric axial load applied, Phd Thesis. Department of Strength of Materials and Engineering Structures. Universitat Politècnica de Catalunya, BarcelonaTECH, 2013.

[32] P. Larrinaga, Flexural strengthening of low grade concrete through the use of new cement-based composite materials, Phd Thesis. E.T.S.I. de Bilbao. Universidad del País Vasco, 2011.

[33] Japan Society of Civil Engineers (JSCE), JSCE-SF4. Method of tests for flexural strength and flexural toughness of steel fiber reinforced concrete, Concrete Library of JSCE. 3 (1984) 58-61.

[34] E. Bernat, C. Escrig, C.A. Aranha, L. Gil, Experimental assessment of Textile Reinforced Sprayed Mortar strengthening system for brickwork wallettes, Construction and Building Materials. 50 (2014) 226-236.

[35] Comité Européen de Normalisation, Eurocode 2. Design of concrete structures - Part 1: Common rules for building and civil engineering structures, (2004).

[36] A. Khalifa, W.J. Gold, A. Nanni, A.A. M.I., Contribution of externally bonded FRP to shear capacity of RC flexural members, Journal of Composites for Construction. 2 (1998) 195-202.

[37] T.C. Triantafillou, C.P. Antonopoulos, Design of concrete flexural members strengthened in shear with FRP, Journal of Composites for Construction. 4 (2000) 198-205.

[38] ACl Committee 318, ACl 318-11 - Building Code Requirements for Structural Concrete, (2011). 
1 List of tables

2 Table 1. Mechanical properties of the concrete and steel bars.

3 Table 2. Mechanical properties of the mortars used as TRM matrices.

4 Table 3. Properties of the fibres and textiles.

5 Table 4. TRM combinations used as shear reinforcement of RC beams.

6 Table 5. Mechanical properties of TRM strengthening composite materials.

7 Table 6. Summary of the experimental results.

8 Table 7. Relative error between the experimental results and the analytical predictions of the shear

9 resistance contribution provided by the TRM reinforcements (absolute values).

10 Table 8. Experimental data on the shear strengthening of RC beams with TRM.

11 Table 9. $A$ and $B$ values related to the strengthening configuration of the reinforcement. 
1 List of figures

2 Figure 1. Geometry and steel reinforcement of the tested beams (all dimensions in $\mathrm{mm}$ ).

3 Figure 2. Textiles used: (a) basalt, (b) carbon, (c) PBO and (d) glass.

4 Figure 3. TRM application process.

5 Figure 4. Test set-up (all dimensions in $\mathrm{mm}$ ).

6 Figure 5. Test instrumentation: (a) sketch, (b) picture (all dimensions in $\mathrm{mm}$ ).

7 Figure 6. Failure modes of tested beams.

8 Figure 7. Normalized shear force vs. vertical displacement of the load application sections: (a) failure mode

9 A, (b) failure mode B and (c) failure mode C. The unstrengthened beam is included in all cases.

10 Figure 8. Deflexion of the tested beams at a load of $100 \mathrm{kN}$.

11 Figure 9. Absorbed energy for vertical displacements of the load application section of $L / 150$ and L/100,

12 except for V-CONTROL, which did not reach these values.

13 Figure 10. Real shear strain increase and theoretical shear strain increase vs. load increase: (a) BR3, (b)

14 CXM25, (c) PXM750 and (d) GPHDM.

15 Figure 11. Experimental and analytical shear resistance contributions of the TRM reinforcements: (a) BR3, 16 (b) CXM25, (c) PXM750 and (d) GPHDM.

17 Figure 12. TRM normalized strain $\varepsilon_{f e, \text { TRM }} / \varepsilon_{f i b}$ Vs. $E_{f i b} \rho_{t e x} / f_{c m}{ }^{(2 / 3)}$ 